\title{
WestVirginiaUniversity
}

THE RESEARCH REPOSITORY @ WVU

Graduate Theses, Dissertations, and Problem Reports

2008

\section{Postpartum sleep disturbance and psychomotor vigilance performance}

Salvatore Insana

West Virginia University

Follow this and additional works at: https://researchrepository.wvu.edu/etd

\section{Recommended Citation}

Insana, Salvatore, "Postpartum sleep disturbance and psychomotor vigilance performance" (2008). Graduate Theses, Dissertations, and Problem Reports. 2633.

https://researchrepository.wvu.edu/etd/2633

This Thesis is protected by copyright and/or related rights. It has been brought to you by the The Research Repository @ WVU with permission from the rights-holder(s). You are free to use this Thesis in any way that is permitted by the copyright and related rights legislation that applies to your use. For other uses you must obtain permission from the rights-holder(s) directly, unless additional rights are indicated by a Creative Commons license in the record and/ or on the work itself. This Thesis has been accepted for inclusion in WVU Graduate Theses, Dissertations, and Problem Reports collection by an authorized administrator of The Research Repository @ WVU. For more information, please contact researchrepository@mail.wvu.edu. 
Postpartum Sleep Disturbance and Psychomotor Vigilance Performance

\author{
Salvatore Insana \\ Thesis submitted to the \\ Eberly College of Arts and Sciences \\ at West Virginia University \\ In partial fulfillment of the requirements \\ for the degree of
}
Master of Science
in
Psychology

\author{
Hawley Montgomery-Downs, Ph.D., Chair \\ Barry Edelstein, Ph. D. \\ Katherine Karraker, Ph. D.
}

\begin{abstract}
Department of Psychology
\end{abstract}
Morgantown, West Virginia
2008

Keywords: postpartum, mothers, sleep, sleep fragmentation, psychomotor vigilance 


\begin{abstract}
Postpartum Sleep Disturbance and Psychomotor Vigilance Performance
\end{abstract}

Salvatore Insana

Postpartum women have high rates of sleep disturbance and commonly suffer from many of the effects of disturbed sleep, though attentional state has not been studied extensively in this population. This study assessed sleep and attentional state psychomotor performance in postpartum women to develop a better understanding of how sleep disturbance -specifically sleep fragmentation and partial sleep deprivation- is associated with attentional state psychomotor performance. Participants were a sample of 24 postpartum mothers from a larger study. Mothers were $29.96(S D=7.94)$ years old, had a mean income of $\$ 65,808(S D=$ $\$ 41,398)$, and had $17.04(S D=2.53)$ years of education. Of these women, $95.83 \%$ lived with their partner, $91.67 \%$ were white, and 50\% were primiparious. Data were collected from 8 through 15 weeks postpartum, inclusive. Mothers wore an actigraph on their non-dominant wrist to record their sleep and recorded their sleep and wake behaviors in an electronic diary. Mothers completed a psychomotor vigilance test (PVT) each morning within 2 hours of awakening and before consuming caffeine. Overall, mothers obtained a reasonable amount of 24 hour sleep (7 hours and 36 minutes); however, this sleep was fragmented $(M=14.19, S E=.16)$. Additionally, mothers performed poorly on the PVT (Reaction time: $M=397.52$, msec. $S E=2.61$; Percent lapses $M=15.89, S E=.52$ ) when compared to normative values. Results indicate that sleep time and sleep fragmentation from the previous night are not associated with attentional based psychomotor performance the following day in this sample of women. Across postpartum weeks 8-16 the amount of sleep obtained remained the same; however, across time it became less fragmented $(p<.001)$ and was obtained in more consolidated periods. The current study provides objective data regarding the amount of sleep fragmentation in postpartum women and describes how sleep fragmentation changes across postpartum weeks 8-16. Additionally, this study indicates that postpartum women perform poorly on the PVT, yet they obtain a reasonable amount of sleep time. 


\section{TABLE OF CONTENTS}

TITLE PAGE.

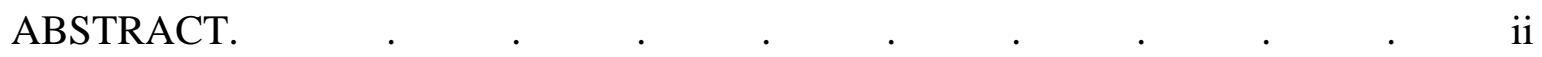

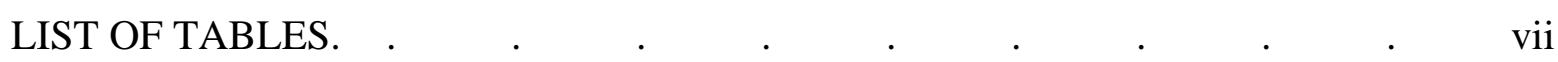

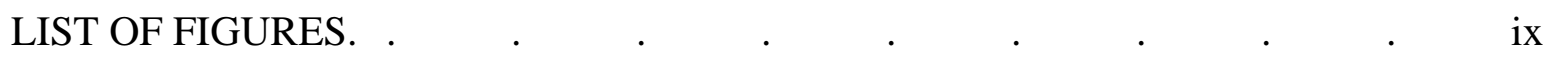

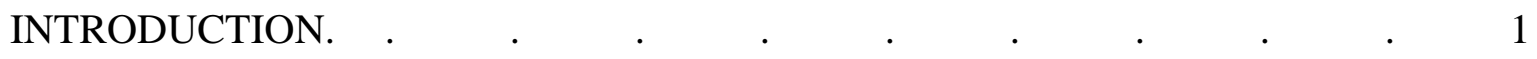

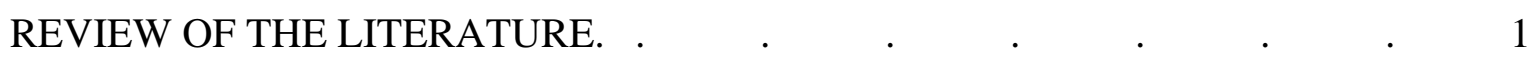

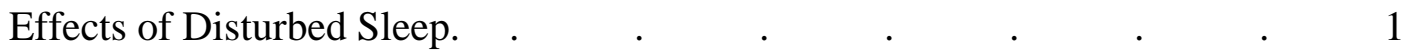

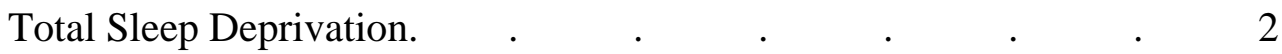

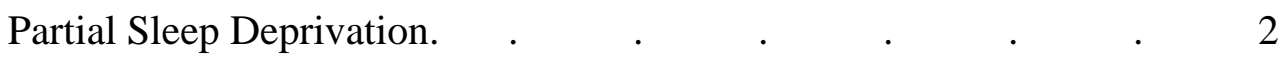

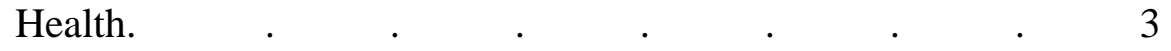

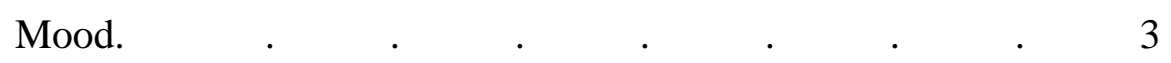

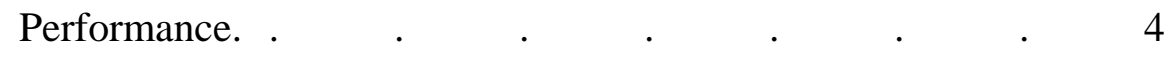

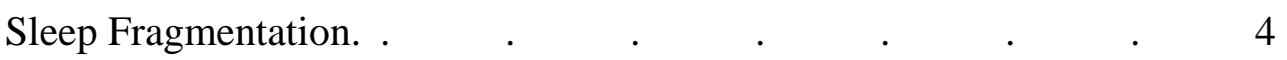

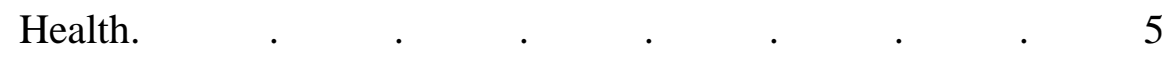

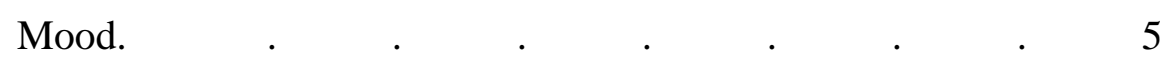

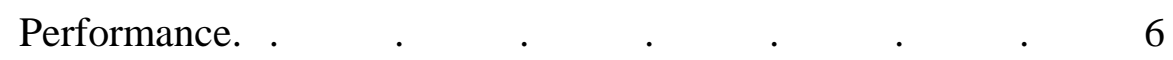

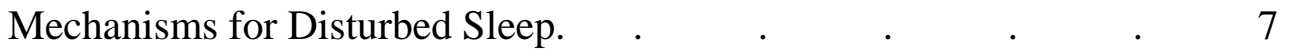

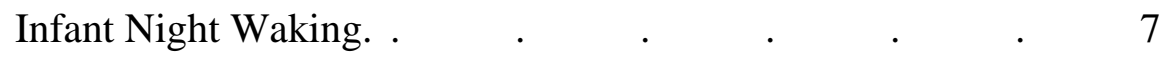

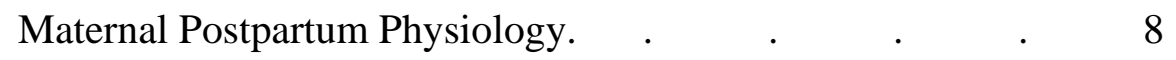

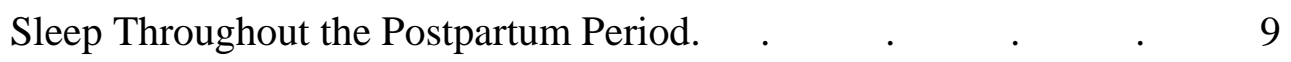

Effects of Postpartum Sleep Disturbance. $\quad$. $\quad$ • $\quad$. $\quad$. 10

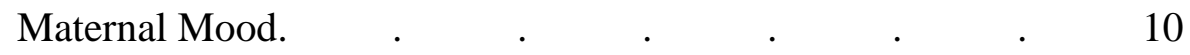




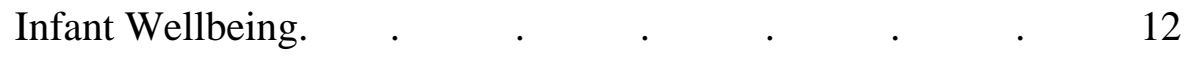

Objective Assessment of Sleep and Attentional State. $\quad . \quad$ $\quad$. $\quad 13$

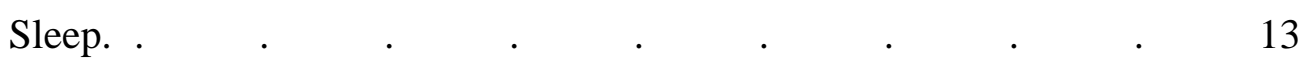

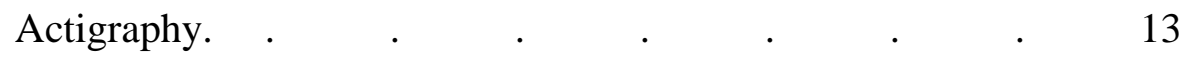

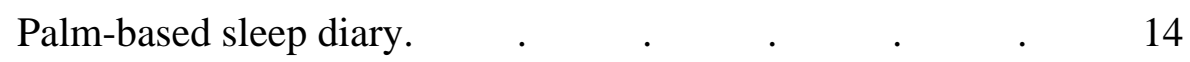

Performance: Psychomotor Vigilance Test (PVT). . $\quad$. $\quad$. 14

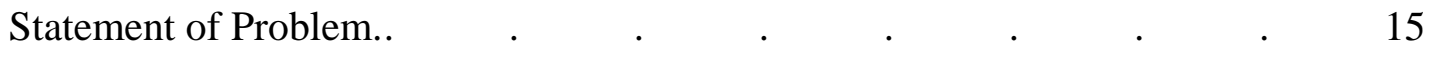

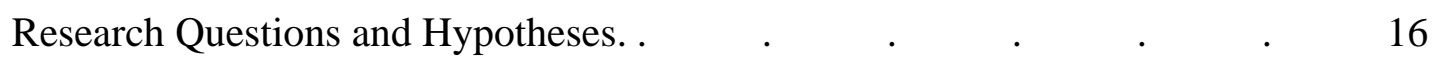

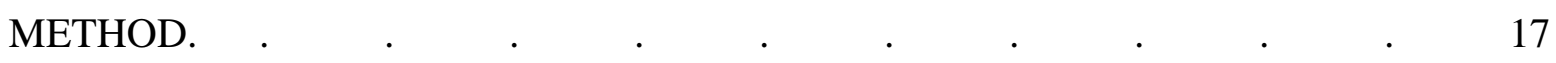

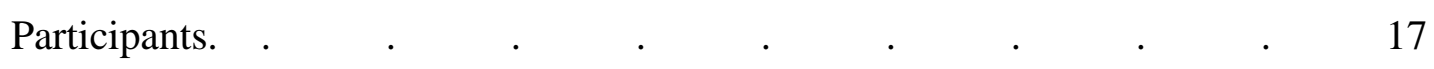

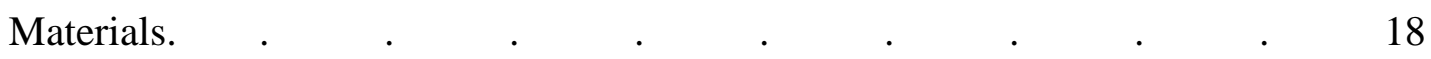

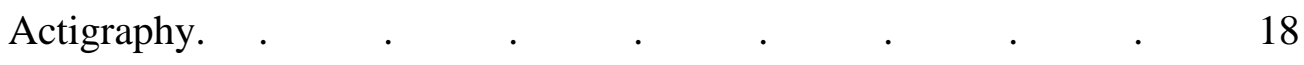

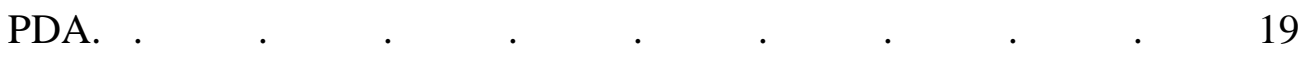

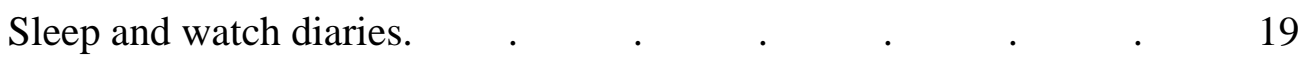

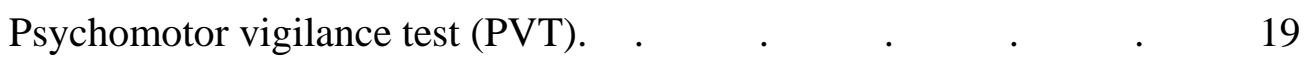

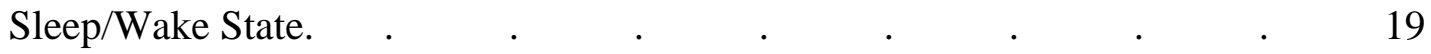

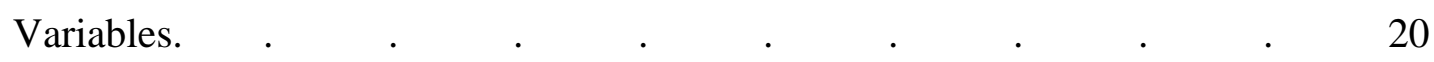

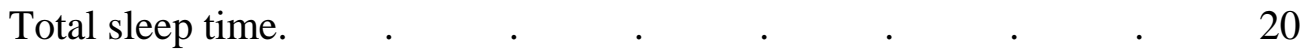

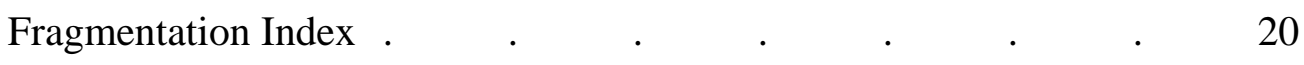

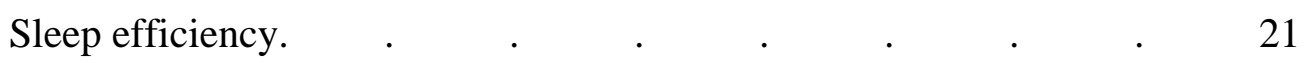

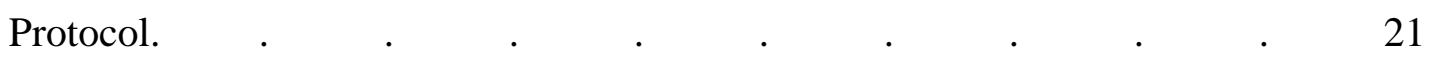

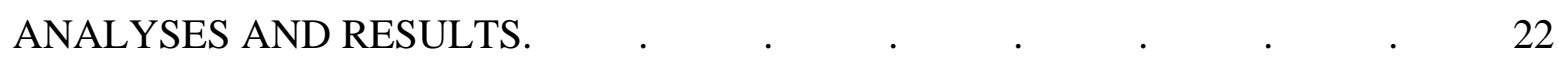

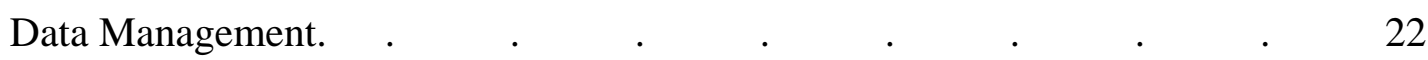




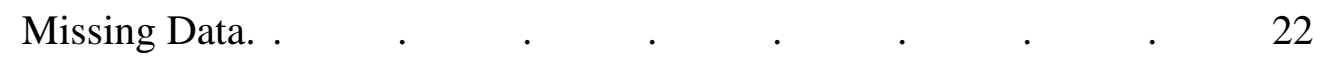

Upper (extreme) and lower (false start) reaction time values. $\quad$. $\quad 22$

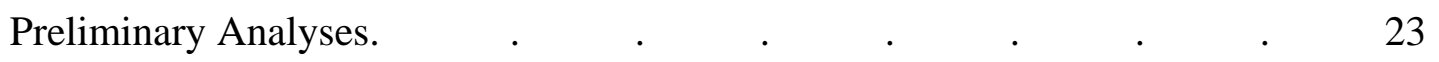

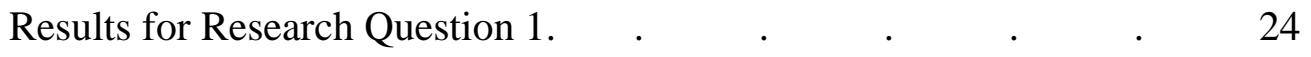

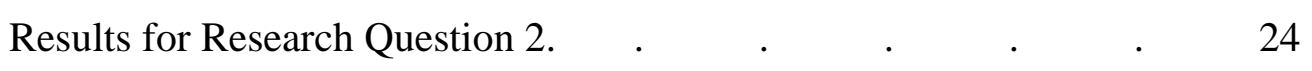

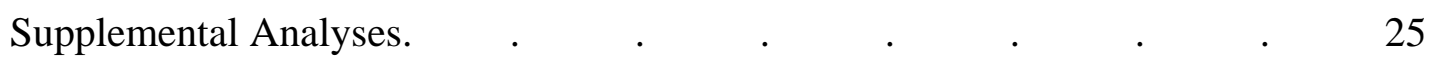

Change in sleep variables across

postpartum weeks 8 through $12 . \quad$. $\quad . \quad$. $\quad . \quad$. $\quad . \quad 26$

Change in performance variables across

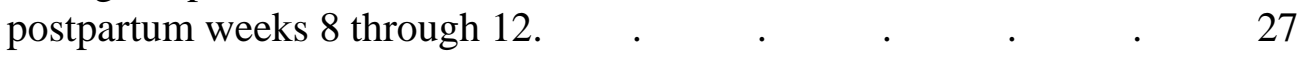

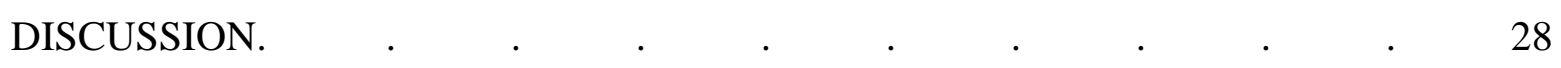

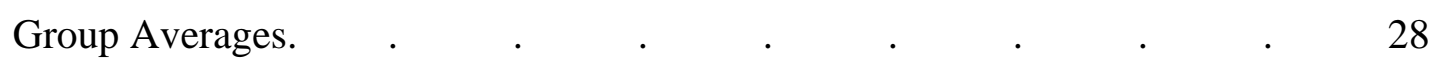

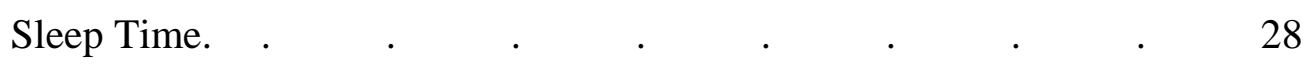

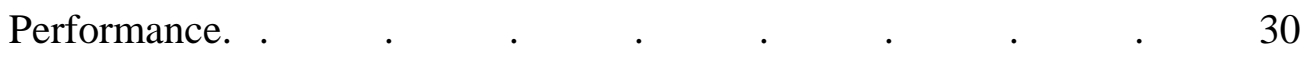

Sleep and Psychomotor Performance Variables. $\quad . \quad$. $\quad$. $\quad$. 31

Intercorrelations within sleep and

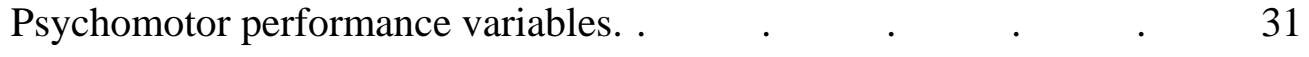

Intracorrelations between sleep and

Psychomotor performance variables. . $\quad . \quad$. $\quad . \quad$. 32

Change in Sleep and Psychomotor Performance Variables. . 32

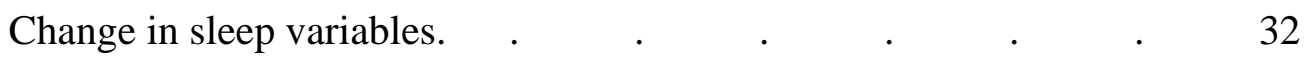

Change in psychomotor performance variables. $\quad . \quad$. $\quad . \quad 33$

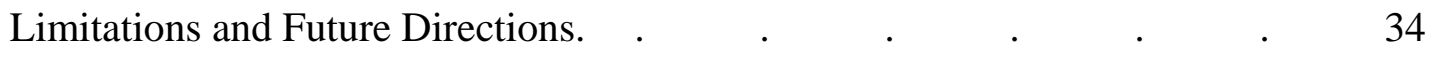

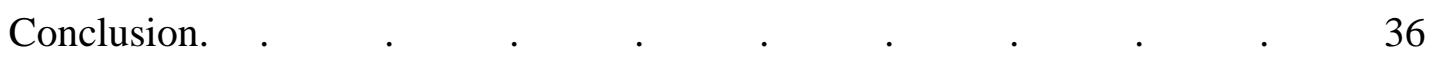

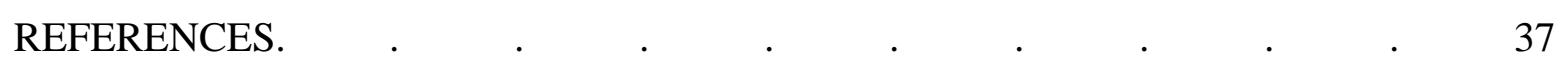




\section{LIST OF TABLES}

1. Descriptive Statistics for Sleep and Performance Variables. . 46

2. Intercorrelations Between Sleep and Performance Variables. $\quad$ • 47

3. 24 Hour Total Sleep Time Values for Unweighted

Linear, Quadratic and Cubic Trend Analyses. $\quad . \quad$. $\quad . \quad$. 48

4. Nocturnal Sleep Time Values for Unweighted Linear, Quadratic and Cubic Trend Analyses.

5. Sleep Fragmentation Values for Unweighted Linear, Quadratic and Cubic Trend Analyses.

6. Sleep Efficiency Values for Unweighted Linear, Quadratic and Cubic Trend Analyses.

7. Mean Reaction Time Values for Unweighted Linear, Quadratic and Cubic Trend Analyses.

8. Percent Lapse Values for Unweighted Linear, Quadratic and Cubic Trend Analyses.

9. Percent False Start Values for Unweighted Linear, Quadratic and Cubic Trend Analyses.

10. Intercorrelations Between Sleep and

Performance Variables: Week Eight Postpartum.

11. Intercorrelations Between Sleep and Performance Variables: Week Nine Postpartum. . $\quad . \quad$. $\quad . \quad$. 56

12. Intercorrelations Between Sleep and Performance Variables: Week Ten Postpartum.

13. Intercorrelations Between Sleep and Performance Variables: Week Eleven Postpartum.

14. Intercorrelations Between Sleep and Performance Variables: Week Twelve Postpartum.

15. Intercorrelations Between Sleep and Performance Variables: Week Thirteen Postpartum. 
16. Intercorrelations Between Sleep and Performance Variables: Week Fourteen Postpartum.

17. Intercorrelations Between Sleep and Performance Variables: Week Fifteen Postpartum. 


\section{LIST OF FIGURES}

1. Average total sleep time with standard error bars across postpartum weeks eight through fifteen.

2. Average nocturnal sleep time with standard error bars across postpartum weeks eight through fifteen.

3. Average nocturnal sleep fragmentation with standard error bars across postpartum weeks eight through fifteen.

4. Average nocturnal sleep efficiency with standard error bars across postpartum weeks eight through fifteen. $\quad . \quad$ c $\quad . \quad$. $\quad$. 66

5. Average reaction time with standard error bars across postpartum weeks eight through fifteen.

6. Percent lapses per trial with standard error bars across postpartum weeks eight through fifteen.

7. Percent false starts per trial with standard error bars across postpartum weeks eight through fifteen.

8. Scatter plot of total sleep time and percent false starts within postpartum week ten. . 
Introduction

Sleep disturbance can have deleterious effects on health, mood, and basic cognitive processes. Postpartum women have high rates of sleep disturbance and commonly suffer from many of the effects of disturbed sleep, though attentional state has not been studied extensively in this population. This study assessed sleep and attentional state psychomotor performance in postpartum women to develop a better understanding of how sleep disturbance -specifically sleep fragmentation or partial sleep deprivation- is associated with attentional state psychomotor performance.

Sleep deprivation and fragmentation are discussed below as specific forms of disturbed sleep. Infant night waking and maternal physiological alterations are then briefly reviewed as mechanisms for disturbed postpartum sleep, followed by a discussion of the effects of postpartum sleep disturbance. Background on the measures used to assess sleep and attentional state psychomotor performance is provided. Finally, a rationale for the study is stated.

$$
\begin{aligned}
& \text { Review of the Literature } \\
& \text { Effects of Disturbed Sleep }
\end{aligned}
$$

The typical normally functioning adult requires approximately 7-8 hours of sleep per night (Ferrara \& De Gennaro, 2001). However, there are individual differences in the amount of sleep needed. These individual differences are influenced by factors that include, but are not limited to, biology, culture, and lifestyle. In addition, the amount and structure of sleep changes greatly throughout the lifespan (Ohayon et al., 2004).

Sleep can be disturbed by a variety of factors and result in total sleep deprivation, partial sleep deprivation, and/or sleep fragmentation. Postpartum women have high rates of sleep disturbance and therefore were selected as the focus of the present study. Disturbed sleep is 
associated with decrements in health, mood, and cognitive processing. In the following sections, the different forms of disturbed sleep are defined and their various adverse effects on health, mood, and cognitive performance are summarized. The adverse effects of sleep disturbance on performance was the focus of this study. Sleep in postpartum women is typically disturbed by partial sleep deprivation and sleep fragmentation; therefore, a primary focus was on these two forms of disturbed sleep.

\section{Total Sleep Deprivation}

In total sleep deprivation conditions, no sleep is obtained for 24 hours or more following the previous wake period (Drummond \& Orff, 2005). Total sleep deprivation in humans is typically acute, or temporary and has deleterious hormonal, pulmonary, behavioral, and alertness effects (Bonnet \& Arand, 2003). Studies of chronic total sleep deprivation have been conducted with animals. In a classic study by Rechtschaffen and colleagues, experimentally induced chronic total sleep deprivation in rats was associated with ulcerative lesions, impaired thermoregulation, increased food intake, increased weight loss, increased energy expenditure, debilitated appearance, and ultimately shock and death (Rechtschaffen, Bergmann, Everson, Kushida, \& Gilliland, 1989).

Partial Sleep Deprivation

Partial sleep deprivation occurs when some sleep is obtained during a 24-hour period, but not enough to meet an individual's daily sleep need (Landis, 2005). Partial sleep deprivation is common and can be acute or chronic. Generally, acute partial sleep deprivation is temporary partial sleep loss that lasts for one or a few nights, whereas chronic partial sleep deprivation persists for at least a week (Drummond \& Orff, 2005). Unless sleep is experimentally restricted, partial sleep deprivation can only be inferred because the amount of restriction is a function of an 
individual's typical sleep need. Of particular note, acute partial sleep deprivation has more severe effects on mood and cognitive performance than does acute total sleep deprivation (Pilcher \& Huffcutt, 1996). The effects of partial sleep deprivation on health, mood, and performance are discussed separately below.

\section{Health}

Short sleep duration is associated with various health consequences. For example, in a group of healthy participants, consistent short sleep durations (i.e. less than 7 hours) were associated with higher rates of all-cause mortality (Tamakoshi \& Ohno, 2004). The reason for the association between shortened sleep periods and shortened lifespan is unknown, though a relation between short sleep durations and immune system dysfunctions have been reported (Motivala \& Irwin, 2007). For example, partial sleep deprivation was found to decrease immunological response to an influenza vaccination (Spiegel, Sheridan, \& Van Cauter, 2002). Similarly, short sleep duration has been found to be associated with an elevated prevalence of obesity (Singh, Drake, Roehrs, Hudgel, \& Roth, 2005). Experimentally induced partial sleep deprivation is also associated with a change in hormones that regulate appetite including reduced leptin and elevated ghrelin (Taheri, Lin, Austin, Young, \& Mignot, 2004). These authors also found that short habitual sleep was associated with an increased body mass index. Together, short sleep durations have been associated with adverse health consequences.

\section{Mood}

Experimentally induced partial sleep deprivation has shown negative effects on mood. Participants who were restricted to $4-5$ hours of sleep per night for 7 consecutive nights demonstrated worsened Profile of Mood States subscales for fatigue-inertia, confusionbewilderment, tension-anxiety, and total mood disturbance (Dinges et al., 1997). A meta-analysis 
of the effects of total and partial sleep deprivation on functioning revealed that mood is more negatively affected by partial sleep deprivation than is cognitive performance (Pilcher \& Huffcutt, 1996).

\section{Performance}

Partial sleep deprivation also has a significant negative impact on neurocognitive performance. A minimum duration of uninterrupted sleep may be necessary to maximize sleep's neurocognitive benefits (Franken, 2002; Stepanski, 2002). Sleep deprivation appears to have a dose response effect on a basic reaction time task as measured by the psychomotor vigilance test (PVT) with greater sleep deprivation resulting in greater performance impairment (Belenky et al., 2003). Van Dongen and colleagues demonstrated that partial sleep deprivation for 6 hours per night for two consecutive weeks produced psychomotor vigilance deficits that were similar to those seen after 24 hours of total sleep deprivation (Van Dongen, Maislin, Mullington, \& Dinges, 2003). The cumulative negative effects of partial sleep deprivation on cognitive performance tasks such as the PVT are well documented (Dinges, Rogers, \& Baynard, 2005).

\section{Sleep Fragmentation}

Sleep fragmentation is the result of brief periodic arousals from sleep that reduce total sleep time but maintain the normal time in bed (Drummond \& Orff, 2005). Sleep fragmentation is identified by a short stage shift or arousal from sleep (brief wake) when measured using the 'gold standard' Polysomnography (PSG). As discussed below, sleep fragmentation can also be

identified by actigraphy. According to Bonnet's (1986) the Sleep Continuity Theory a period of uninterrupted sleep is required for sleep to be restorative. Interrupted sleep can be caused by organic factors (e.g. physiological alterations), or environmental events (e.g. crying baby) (Bonnet, 2005a). As reviewed by Bonnet and Arand (2003), the adverse effects of sleep 
fragmentation are due to the disturbance of sleep continuity, not the decrease in sleep length, or the changes in sleep stage (i.e. shifting into wake from stages of sleep). For this reason we hypothesize that sleep fragmentation will have a greater negative effect on performance values than sleep time.

Sleep fragmentation is known to have negative effects on daytime functioning (Stepanski, 2002). For example, Stepanski and colleagues demonstrated an association between sleep fragmentation and subsequent daytime sleepiness (Stepanski, Lamphere, Badia, Zorick, \& Roth, 1984). While maintaining the same amount of sleep time across conditions, experimentally induced high-frequency sleep fragmentation can produce similar negative effects on health and performance as total sleep deprivation (for a review see Bonnet, 2005b). The effects of sleep fragmentation on health, mood, and neurocognitive performance are discussed below.

\section{Health}

Like other forms of sleep disturbance, sleep fragmentation has adverse health effects. As the rate of sleep fragmentation increases, the restorative capacity of sleep decreases and sleepiness increases (Levine, Roehrs, Stepanski, Zorick, \& Roth, 1987). Sleep loss caused by sleep fragmentation raises risk for metabolic alterations, weight gain, insulin resistance, and Type 2 diabetes (Spiegel, Knutson, Leproult, Tasali, \& Van Cauter, 2005). Experimentally induced sleep fragmentation increases the stress hormones cortisol and ACTH (Spath-Schwalbe, Gofferje, Kern, Born, \& Fehm, 1991).

\section{Mood}

Bonnet (1985) demonstrated that two nights of experimentally induced sleep fragmentation degraded mood and performance to lower levels than those seen after one night of total sleep deprivation. The findings were of particular interest because participants only lost 
approximately one hour of sleep per night as a result of induced sleep fragmentation. These results indicate the importance of sleep continuity and support the Sleep Continuity Theory. One night of experimentally induced sleep fragmentation lead to both decreased mood and impaired cognitive performance during the subsequent day (Martin, Engleman, Deary, \& Douglas, 1996).

\section{Performance}

Sleep fragmentation can result in neurocognitive performance decrements as significant as those from partial sleep deprivation (Durmer \& Dinges, 2005). Decrements in psychomotor performance tasks due to sleep fragmentation are consistently reported in the literature (for review see Bonnet, 2005b.). Bonnet (1986) demonstrated the effects of experimentally induced sleep fragmentation on several performance tasks, including reaction time. Participants were briefly awakened after each 1-minute, 10-minute, or 2.5-hour sleep period, or underwent total sleep deprivation. On the subsequent day reaction time performance decreased as fragmentation increased across conditions. After two nights in the 1-minute arousal condition participants showed reaction times similar to those in the total sleep deprivation condition. This study demonstrated how the cumulative effect of frequent arousals from sleep can have a marked effect on performance variables similar to those seen during sleep deprivation.

In summary, both discrete sleep deprivation and sleep fragmentation have a negative impact on health, mood, and performance. There are many causes of sleep disturbance, such as sleep fragmenting disorders; however, causes of sleep disturbance specific to postpartum women are discussed next. Postpartum mothers are the focus of this study because they serve as a naturally occurring model for sleep disturbance in the absence of fragmenting sleep disorders such as obstructive sleep apnea, restless legs syndrome, and periodic limb movement disorder. 


\section{Mechanisms for Disturbed Postpartum Sleep}

Maternal postpartum sleep disturbance is common (Santiago, Nolledo, Kinzler, \& Santiago, 2001). Postpartum sleep disturbance is most likely a combination of responding to the needs of the infant whose sleep cycles are markedly different from those of the typical adult, and maternal physiological alterations. Infant night waking that follows the completion of their sleep cycle can result in signaling that would wake the mother. Additionally infants may signal to their parents for the purpose of nutritional needs during the night, which can also lead to waking of the mother. Maternal physiological alterations refer to the hormonal milieu of the 'fourth trimester' and beyond, that is, postpartum hormonal patterns may lead to disturbed sleep. These two contributors to postpartum sleep disturbance will be discussed below.

\section{Infant Night Waking}

Infant night waking is a factor that may contribute to maternal sleep deprivation. All infants awaken from sleep and either signal for the caregiver (cry and wake the caregiver for intervention), or self-soothe (return to sleep without caregiver intervention). When infants signal rather than self-sooth following an awakening, they awaken their mothers.

Newborn infants spend roughly the same amount of time sleeping as they do awake, and sleep in early infancy is evenly dispersed across the 24-hour period (Montgomery-Downs \& Gozal, 2006; Jenni \& Carskadon, 2005). Infant circadian rhythmicity begins to develop during the first 5 to 6 weeks following birth when waking becomes more consolidated during the day and sleep is more consolidated during the night (Peirano, Algarin, \& Uauy, 2003). From birth to two years, 24-hour sleep durations remain relatively the same; however, the temporal distribution of sleep changes such that naps and nocturnal awakenings decrease and nocturnal sleep increases, thus 24-hour sleep consolidates into the nocturnal periods (Montgomery-Downs \& 
Gozal, 2006). With marked individual differences, infant nocturnal sleep predominates by around 4 months of age. A link has been found between maternal sleep fragmentation and the circadian sleep rhythm formation in infants (Nishihara, Horiuchi, Eto, \& Uchida, 2000).

Specifically, up to 3 months of age infant sleep cycles are roughly 45 to 60 minutes long (Sheldon, 2005), whereas adult sleep cycles are roughly 60-90 minutes long.

At the end of each sleep cycle a brief period of waking occurs, which may lead to infant signaling or self-soothing. If infants signal for the caregiver following a 60-minute sleep cycle, the 90-minute adult sleep cycle will inevitably be interrupted regardless of exact coordination or not; however, the exact coordination of infant and adult sleep cycles is unlikely. Infants who signal following their sleep cycles have been found to interrupt and fragment maternal sleep (Nishihara, Horiuchi, Eto, \& Uchida, 2002). When parental sleep patterns and fatigue were compared during and after pregnancy; both parents reported higher fatigue and more sleep disturbances immediately after pregnancy (Gay, Lee, \& Lee, 2004). In sum, infants who signal during night waking promote, at least in part, sleep loss and specifically sleep fragmentation in their caregivers.

\section{Maternal Postpartum Physiology}

In addition to the effects of infant night waking, sleep in postpartum mothers may also be affected by physiological alterations due to pregnancy and childbirth. In one study when mothers slept away from their infants, sleep disruption continued, which may be due to physiological factors such as various hormonal regulations (Karacan, Williams, Hursch, McCaulley, \& Heine, 1969; Manber \& Armitage, 1999). Physiologic changes that occur during pregnancy may have significant influences on sleep after birth. For example, throughout pregnancy cortisol, estrogen, and progesterone levels increase: high cortisol is associated with stress and depressive 
symptoms; high estrogen is associated with less REM sleep, fewer night wakings, longer sleep times, and a decrease in sleep latency; and progesterone has a sedative effect and is known to increase non-REM sleep (Manber \& Armitage, 1999). The sleep promoting effects of estrogen and progesterone are highest during late pregnancy and decrease immediately after delivery (Manber \& Armitage, 1999; Ross, Murray, \& Steiner, 2005). From a homeostatic viewpoint the precipitous decrease in these hormones after delivery challenges the body to make up for the absence of their sleep promoting effects.

\section{Sleep Throughout the Postpartum Period}

Within the sleep literature, the postpartum period is defined as anywhere from the first 6 months after delivery (Wolfson \& Lee, 2005) up to 2 years after delivery (as reviewed in Ross et al., 2005). Regardless of how the postpartum period is defined, sleep disturbance is documented among postpartum mothers. According to a poll by the National Sleep Foundation, 55\% of postpartum women surveyed reported getting a good night's sleep only a few nights a month or less, $68 \%$ reported having been awake a lot during the night at least a few nights a week, and $38 \%$ reported having driven drowsy at least once a month (National Sleep Foundation [NSF], 2007). NSF did not operationally define their use of the term "postpartum period;" however, $92 \%$ of women in the postpartum sample had a child 6 months old or younger.

Although sleep is known to worsen from the first trimester to the third trimester of pregnancy, it becomes most problematic after delivery (Ross et al., 2005). Kang and colleagues conducted a longitudinal assessment of sleep in mothers from 5 weeks before delivery through 15 weeks postpartum and found the highest levels of sleep disturbance during the initial postpartum weeks (Kang, Matsumoto, Shinkoda, Mishima, \& Seo, 2002). The highest incidences of sleep fragmentation are found during the second week postpartum, which then decrease in 
frequency from that point forward (Shinkoda, Matsumoto, \& Park, 1999). These authors speculate that during the second week of the postpartum period the infant feeding and sleepwake cycles begin to synchronize with the variation of day and night. In a 2005 review, Gaylor and Manber report that sleep during the postpartum period is most impeded by fragmentation. These authors go on to explain that fragmented sleep gradually decreases across the first three months postpartum, but improvement is most pronounced during 6-12 months postpartum. Overall, postpartum mothers have high sleep disturbance after delivery, which then begins to decrease months into the postpartum period. Again, postpartum sleep disturbance is most likely a combination of responding to the needs of the infant and maternal physiological / hormonal alterations.

Effects of Postpartum Sleep Disturbance

As previously discussed, postpartum women are highly vulnerable to sleep disturbance. This is an important problem because disturbed sleep in postpartum mothers can lead to symptoms of depressed mood and potentially threaten mother and infant well-being.

\section{Maternal Mood}

Up to $85 \%$ of postpartum women report having experienced an increase in negative mood and 10-15\% reach the diagnostic criteria for depression (Ross et al., 2005). Overall, more sleep loss in postpartum women appears to be associated with increased dysphoric mood states (Swain et al., 1997). More specifically, among postpartum women higher levels of sleep fragmentation are associated with more negative mood states (Lee, McEnany, \& Zaffke, 2000). After a review of the literature, Armstrong and colleagues propose that postpartum women who suffer from chronic sleep disturbance are over-diagnosed as having postpartum depression (Armstrong, Van Haeringen, Dadds, \& Cash, 1998). 
A body of literature supports the idea that infant sleep problems (e.g. extensive night waking and difficulty going to sleep) contribute to the onset of maternal depression. Furthermore, negative mood in postpartum mothers is associated with their previous night's sleep (Swain et al., 1997). Hiscock and Wake (2001) found a relation between maternal depression and maternal sleep disturbance, which they attribute to infant sleep problems, as described above. These researchers later established a behavioral intervention that targeted infant sleep. When mothers implemented the behavioral intervention their depressive symptoms decreased (Hiscock \& Wake, 2002). The cumulative results suggest that infants who have extensive night waking and difficulty going to sleep may contribute to postpartum depression.

Dennis and Ross (2005) found that infant sleep, maternal sleep, and maternal fatigue were strongly associated with higher maternal depressive symptomatology. These researchers speculate that sleep disruption in mothers might precede postpartum depression. The directionality of the association between maternal depression and infant sleep has been explored. Specifically, postpartum mothers may experience depressive symptoms because of disturbed sleep, or they may have disturbed sleep because of depressive symptomology. The direction between postpartum depression and postpartum sleep has been referred to as a 'chicken-egg dilemma' (Armstrong et al., 1998); furthermore, the current state of research does not conclusively identify the direction of relations. A body of research favors the idea that infant sleep problems lead to depressive-like symptoms in postpartum mothers (Dennis \& Ross, 2005; Hiscock \& Wake, 2002). Additional research indicates that mothers with depressive symptamotology are more likely to have less healthy infant sleep practices than mothers without depressive symptamotology (Paulson, Dauber, \& Leiferman, 2006). Depressive symptoms in postpartum mothers are associated with a higher frequency of night waking in 15 to 24 month 
old infants (Warren, Howe, Simmens, \& Dahl, 2006).Karraker and Young (2007) describe the direction between symptoms of postpartum depression and infant sleep as transactional, where simultaneously infant night waking increases symptoms of maternal depression over time and symptoms of maternal depression increases less healthy infant sleep practices, which may promote infant night waking.

\section{Infant well-being}

Another body of literature supports the idea that maternal depression increases compromised infant outcomes. A review of the robust literature on the effects of maternal depression on infant development is beyond the scope of this proposal. However, to emphasize the critical nature of maternal sleep disturbance, it is important to address the effects of maternal depression symptamotology on infant outcomes. As reviewed by Murray and colleagues, postnatal depression is strongly associated with an increase in negative infant-parent interactions and adverse emotional and cognitive outcomes for the infant (Murray, Cooper, \& Hipwell, 2003). A large sample national study revealed that parents with depressive symptamotology are 1.5 times more likely to engage in less positive parent-infant interactions than parents without depressive symptamotology (Paulson et al., 2006). More specifically infants of mothers suffering from postpartum depression have been shown to have more eating and sleeping difficulties, as well as fewer vocal, visual, and physical interactions with their mother (RighettiVeltema, Conne-Perreard, Bousquet, \& Manzano, 2002). Additionally, even among nondepressed mothers at 3 months, fatigue was associated with difficulties in their relationships with their infants. In sum, postpartum sleep disturbances can lead to the adverse health, mood, and performance outcomes, but can also lead specifically to maternal depression that may also threaten infant well-being. 


\section{Objective Assessment of Sleep and Attentional State}

There has been a call for the use of objective measures in postpartum sleep research (Ross et al., 2005). The findings reported here are part of a larger study that used objective measurement techniques to assess both sleep and attentional state psychomotor performance. The measurement techniques used to assess sleep and performance will be briefly reviewed before their detailed description in the methods section to follow.

Sleep

Actigraphy

Actigraphy (activity-based monitoring) was used in the larger study to measure sleep fragmentation and total sleep time. Actigraphs are small motion sensors that are worn like a watch on the non-dominant wrist. Actigraphy is a technique in which general body movements are used to identify periods of sleep and wakefulness. Actigraphy is capable of collecting activity data over relatively prolonged time periods and uses computer-based algorithms to estimate sleep and wake states from activity values. Actigraphy is a reliable instrument for measurement of sleep (Jean-Louis et al., 1997; Kushida et al., 2001; Sadeh \& Acebo, 2002). A recent validation study compared actigraphy to the 'gold standard' sleep measure, Polysomnography (PSG), and found significant agreement between the two measurements of sleep (de Souza et al., 2003).

Due to the use of general body movements to detect sleep, periods of immobility are identified as sleep bouts; similarly, periods of mobility and sleeplessness are identified as wake time. However, actigraphy is highly vulnerable to artifact as in the case when the actigraph is taken off and is motionless. Therefore, it is essential that simultaneous sleep diaries be maintained in order to behaviorally corroborate actigraphy data and to eliminate artifact. 


\section{Palm-based sleep diary}

Behavioral corroboration via sleep diaries allow for a subjective report of sleep periods. Experts recommend that daily behavioral diaries be kept along with actigraphy measures to document bedtimes, rise times, and actigraphy off times (Acebo \& LeBourgeois, 2006; Sadeh \& Acebo, 2002). This practice allows mothers to provide subjective descriptions of their activity and thus a precise interpretation of the motion signal when the researcher analyzes the actigraphy output. The use of a sleep diary in addition to actigraphy is more precise than using actigraphy alone.

Traditional paper-and-pencil behavioral diaries are vulnerable to participant noncompliance when the participants are given a specific protocol to follow. Stone and colleagues compared the compliance rates of Palm-based diaries and traditional paper-pencil diaries used to record behavioral data (Stone, Shiffman, Schwartz, Broderick, \& Hufford, 2002). With the use of paper-pencil diaries, participants accurately recorded their behavioral data within a specified time period only $11 \%$ of the time. Alternatively, with the use of Palm-based diaries, participants accurately recorded their behavioral data during the same specified time period $94 \%$ of the time. These researchers conclude that the use of Palm-based diaries to record behavioral data resulted in higher compliance than paper-pencil diaries.

Palm-based diaries were used in the current study to provide a precise interpretation of the actigraphy motion signal. Palm-based diaries were used rather than paper-pencil diaries because Palm-based diaries are a more effective method to accurately collect behavioral data. Performance: Psychomotor Vigilance Test (PVT).

The Psychomotor Vigilance Test (PVT) is a simple reaction time task developed to measure sustained attention in which a bullseye (stimulus) appears on the screen of a Palm Pilot 
and a button is pressed to make the stimulus disappear (Dinges \& Powell, 1985). Interstimulus intervals are randomly generated. A trial consists of the presentation of 39-56 stimuli and lasts for approximately 5 minutes.

Reaction time as measured by the PVT is a valid method for determining level of attentional state performance impairment (Drummond et al., 2005; Loh et al., 2004; Thorne et al., 2005). Decrements in attentional state are thought to be a result of sleepiness (Pivik, 1991). Reaction time on the PVT has been found to increase as a function of sleep restriction (Belenky et al., 2003). As sleep restriction accumulates, errors of omission, or lapses, increase. Lapses are defined as a reaction time over 500 msec. A lapse is thought to indicate a microsleep (Dinges \& Kribbs, 1991), which is a brief (1-10 second) period of stage 1 sleep that is more likely to occur when sleep deprived (Pivik, 1991). The percentage of lapses in a PVT trial can be used to indicate attentional state performance impairment. Errors of commission, or 'false starts' also increase with sleep restriction. False starts occur when the participant response occurs before the stimulus appears. The percentage of false starts in a PVT trial is another method to assess attentional state performance impairment. In this study the PVT was used for the first time to objectively assess psychomotor performance and attentional state in postpartum women.

\section{Statement of Problem}

The impact of postpartum sleep disturbance on maternal mood and health, and on infant development has been explored. However, the relations between postpartum sleep disturbance and attentional state via psychomotor performance have not been explored (Gaylor \& Manber, 2005). There is also a lack of understanding regarding the frequency and effects of sleep fragmentation in postpartum women. Most reports of nocturnal sleep fragmentation are 
subjective and potentially fallible due to the disturbed sleep; therefore, there is a need for an objective assessment of sleep fragmentation in these women (Ross et al., 2005).

Associations among objective measures of sleep fragmentation, sleep time, and attentional state performance impairment in postpartum women was the focus of the current study. An additional goal of this study was to assess whether sleep fragmentation or total sleep time have a larger impact on attentional state psychomotor performance in postpartum women. The 8-16-week postpartum period is of interest in this study because this is the typical time when postpartum women are expected to return to work. Studies suggest that mothers are still sleeping poorly during this time and may demonstrate impaired attentional state psychomotor performance. This study provides objective insight regarding the sleep and performance of postpartum women during this time.

\section{Research Questions and Hypotheses}

$R Q 1:$ Are higher indices of sleep disturbance positively associated with greater functional impairment in postpartum mothers?

H1 a: Lower total sleep time will be associated with longer mean reaction times on the PVT.

$b$ : Lower total sleep time will be associated with higher percent of lapses on the PVT.

$c$ : Lower total sleep time will be associated with a higher percent of false starts on the PVT.

H2 a: Lower nocturnal sleep time will be associated with longer mean reaction times on the PVT.

$b$ : Lower nocturnal sleep time will be associated with higher percent of lapses on the PVT. $c$ : Lower nocturnal sleep time will be associated with higher percent of false starts on the PVT. 
H3 a: Higher nocturnal sleep fragmentation will be associated with longer mean reaction times on the PVT.

$b$ : Higher nocturnal sleep fragmentation will be associated with higher percent of lapses on the PVT.

$c$ : Higher nocturnal sleep fragmentation will be associated with higher percent of false starts on the PVT.

$R Q 2:$ Is sleep fragmentation or nocturnal sleep time more strongly associated with functional impairment in postpartum mothers?

H4a: Sleep fragmentation will have a greater negative impact on average reaction times than nocturnal sleep time.

$b$ : Sleep fragmentation will have a greater negative impact on percent of lapses than nocturnal sleep time.

c: Sleep fragmentation will have a greater negative impact on percent of false starts than nocturnal sleep time.

Method

\section{Participants}

Participants were a sample of 24 postpartum mothers from a larger study. Mothers were $29.96(S D=7.94$, range $19-40)$ years old, had a mean income of $\$ 65,808(S D=41,398$, range $2,400-180,000)$, and had $17.04(S D=2.53$, range $13-22)$ years of education. Of these women, 95.83\% lived with their partner, $91.67 \%$ were white, and 50\% were primiparious.

Data were collected from 8 through 15 weeks postpartum, inclusive. Mothers were recruited either during their pregnancy or immediately after birth up to 8 weeks postpartum. Mothers were recruited via community advertisements placed to encourage a demographically 
and socioeconomically representative sample. Mothers were excluded based on the following criteria: premature delivery, pregnancy with multiples, infant admission to the neonatal intensive care unit, history of or treatment for major depressive disorder, or a score of $\geq 16$ on the Center for Epidemiologic Studies Depression Scale (CES-D), a 20-item survey used to determine one's current risk for major depressive disorder administered over the phone (Radloff, 1977). Women with preexisting depression or those who were risk for major depressive disorder were excluded because participation in the study would be considered a burden on them and because evaluation of postpartum onset of depressive symptoms was the purpose of the larger study.

Mothers who completed the 8-week protocol received an honorarium of \$280 (equivalent to $\$ 5$ per day). Mothers also received a small gift for their infant at each of the 8 weekly home visits. Women who were ineligible for the study on the basis of preexisting major depressive disorder, or a score of $\geq 16$ on the CES-D were provided information about community resources for evaluation and treatment.

\section{Materials}

\section{Actigraphy}

Continuous, nonintrusive activity was recorded with Mini Mitter's Actiwatch-64 (AW64) actigraphs. Accelerometric sensors within these devices interpret motion using digital integration presented as mathematical calculations. Data were downloaded and calculations were made via a computerized reader and specialized software. The highest resolution setting was used, allowing up to 11 continuous days of monitoring at 15-second epochs. The AW-64 has 64 kbytes of non-volatile memory and is powered by an internal 2030 battery. The AW-64 is $28 \mathrm{x}$ 27 x $10 \mathrm{~mm}$ and weighs 16 grams. Actiware ${ }^{\circledR}$ Software Version 5.4 was used to manage, archive, and analyze AW-64 data. Specifications were provided by Mini Mitter Co., Inc., Bend, Oregon. 


\section{Personal Digital Assistant (PDA)}

A Palm Zire 72 personal digital assistant (PDA) was loaded with software customized for the study. The software was developed in consultation with Bruner Consulting, Inc. The software includes sleep and watch diaries and a PVT.

Sleep and watch diaries.

Sleep and watch diaries for the study were maintained using a computerized experience sampling method; a computerized method that permits participants to record momentary behaviors in daily life (Barrett \& Barrett, 2001) Mothers used the sleep diary to record in real time when they went to bed, when they awoke, when they removed their watches, and when they put them back on. The sleep and watch diaries were used to identify sleep periods on the actigraphy recordings for analyses.

Psychomotor vigilance test (PVT).

Attentional state was assessed using the PVT, administered using a computerized experience sampling method from Ambulatory Monitoring Inc.'s Palm-based React Software. Mean reaction time, percent of lapses (i.e. errors of omission), and percent of false starts (errors of commission) were calculated.

Sleep/Wake State

Periods of nocturnal sleep were identified on the actigraph output with behavioral corroboration by the PDA sleep diary. Sleep onset was identified after two consecutive minutes of no activity on the actigraphy signal that followed the sleep onset time reported in the PDA sleep diary. Conversely, wake was identified after two consecutive minutes of no activity on the actigraphy signal that preceded the wake time reported in the PDA sleep diary. 
Naps were recorded but were not included in the analysis of sleep fragmentation or sleep efficiency because activity during a nap typically leads to the end of that nap period and activity during a nap period is unlikely. However, naps were included in the assessment of total sleep time, where naps were combined with nocturnal sleep time that followed the nap. Once periods of sleep were identified, Actiware software was used to calculate total sleep time, sleep fragmentation, and sleep efficiency indices.

\section{Variables}

\section{Total sleep time.}

Total sleep time is the number of minutes of sleep time during the identified sleep interval. Sleep time is calculated by implementing an algorithm that takes into account the activity recorded from four minutes surrounding each 15 -second epoch analyzed. The generated value from this algorithm is then compared to the "Wake Threshold Value" (manually set) of 40. Thus, if activity was $\leq 40$ that 15 -second epoch was scored as sleep, if the activity count was $>$ 40 that 15 -second epoch was scored as wake. The epochs scored as sleep or wake are then converted into minutes. Sleep time values for both naps and nocturnal sleep were added together to form a 24-hour sleep period representing the total sleep time value. Nocturnal sleep independent of naps was used to represent nocturnal sleep values.

\section{Fragmentation Index.}

The fragmentation index is the amount of activity that occurred between the start time and the end time of the nocturnal sleep interval. This index is derived from the combination of two calculated percentages. First, the algorithm that calculates total sleep time is used to calculate the percentage of epochs scored as movement within the identified nocturnal sleep interval. Second, within the specified sleep interval, an entire minute (four 15-second epochs) is 
scored as movement if a single epoch within that minute is scored as movement; this value is converted into a percent that represents the sleep interval. The two percentages described above are added together to form the fragmentation index.

\section{Sleep efficiency.}

Sleep efficiency represents the percentage of epochs scored as sleep within a sleep interval. A sleep interval is identified according to the actigraph and PDA corroboration as described above. Sleep efficiency is calculated by dividing the 15-second epochs scored as sleep (as indicated above) by the number of epochs that comprise the entire interval scored as sleep expressed as a percent.

\section{Protocol}

Mothers signed an informed consent form, provided Health Insurance Portability and Accountability Act (HIPAA) authorization, and received training on the use of actigraphy and the PDA during an initial prenatal home visit. Mothers who were recruited prenatally were instructed to call the research laboratory following the birth of their child. Participation began within mothers' $8^{\text {th }}$ postpartum week and continued through their $16^{\text {th }}$ postpartum week. Mothers wore an actigraph on their non-dominant wrist at all times except when it might have been submerged in water. Mothers were instructed to record the times when they went to bed and awoke in the morning on the PDA sleep diary, but not nocturnal awakenings. They were also asked to record times when they took the actigraph off. Mothers were instructed to complete the PVT each morning within 2 hours of awakening and before consuming caffeine. During weekly visits the researchers gave the participant a new actigraph and PDA; data from the used equipment was downloaded at the sleep research laboratory. 


\section{Analyses and Results}

The results are reported in five primary sections: data management, preliminary analyses, results for research question 1 , results for research question 2, and supplemental analyses.

\section{Data Management}

\section{Missing Data}

Missing data were randomly present throughout the dataset, that is, data were not concentrated primarily around certain mothers, or certain weeks. However, two mothers (out of $N=24$ ) did not complete the entire eight-week protocol. One of these mothers completed the protocol through week six and the other participant completed the protocol through week five. These incomplete weeks were not included in the following missing data calculations. Overall, $7.45 \%$ of sleep data (91 out of 1,312 nights) were missing, and $13.99 \%$ of reaction time data (161 out of 1,312 reaction time trials) were missing. Data were missing due to equipment malfunction and lack of participant adherence to the research protocol. Due to the nature of the study, when equipment malfunctioned an entire week of data was lost. Missing values were not imputed; instead pairwise deletion was used in the analyses.

\section{Upper (extreme) and lower (false start) reaction time values:}

Prior to the calculation and analysis of reaction time values, response time parameters were set to minimize the effect of extreme responses (Ratcliff, 1993). Reaction time parameters were established on both ends of the reaction time distribution; that is, for both short and long reaction time responses within each trial.

Reaction time responses less than or equal to a reaction time of $100 \mathrm{msec}$ were converted and calculated as false starts within the corresponding trial because these responses are physiologically impossible and therefore denote a response preceding the stimulus ([i.e. an error 
of commission] Doran, Van Dongen, \& Dinges, 2001; H. Van Dongen, personal communication, November 17, 2007). Overall, 20 out of 53,649 (i.e. $<.04 \%$ ) total reaction time responses were recoded as false starts.

As part of the protocol, mothers were instructed to discontinue a PVT response trial if an extraneous event occurred (e.g. phone rings). This instruction allowed for the possibility of long reaction times that reflected neglect of the PVT rather than actual psychomotor performance. Therefore, reaction time responses $\geq 1,314$ msec were excluded from the calculation of reaction time values for each trial. This upper level cutoff value was based on two standard deviations $(S D=439.56 \mathrm{msec})$ above the mean for all of the data ([435.02 msec] Ratcliff, 1993). Overall, 986 out of 53,649 (i.e. $1.84 \%$ ) reaction time responses were excluded from the calculation of reaction time values for each trial.

Sleep data were screened for outliers due to equipment malfunction, such as sleep periods with $0 \%$ or $100 \%$ sleep/fragmentation. Overall, 14 out of 1,312 (i.e. $<1.07 \%)$ nights of data were excluded due to equipment malfunction that yielded incorrect values. In order to preserve meaningful data within extreme scores, no further statistical techniques were used to remove outliers from the sleep data.

Preliminary Analyses

Descriptive statistics were calculated for sleep and performance variables (see Table 1). The distribution of the data was checked for normality by means of skewness $<3$ and kurtosis $<$ 10 (Howell, 2002). The data were also assessed for bimodal distribution; overall the data appeared to be normally distributed. 


\section{Results for Research Question 1.}

Research Question 1: Are higher indices of sleep disturbance positively associated with greater functional impairment in postpartum mothers?

Bivariate correlations were used to examine the associations between total sleep time (including naps), nocturnal sleep time (excluding naps), and sleep fragmentation (nocturnal sleep) on each measure of performance on the PVT, including average reaction times, percentage of lapses, and percent of false starts. Correlations between all variables can be found in Table 2 .

Hypotheses 1a, 1b, and 1c were not supported; 1 a: Lower total sleep time was not associated with longer mean reaction times on the PVT; $1 b$ : Lower total sleep time was not associated with higher percent of lapses on the PVT; $1 c$ : Lower total sleep time was not associated with a higher percent of false starts on the PVT.

Likewise, hypotheses $2 \mathrm{a}, 2 \mathrm{~b}$, and $2 \mathrm{c}$ were not supported; $2 a$ : Lower nocturnal sleep time was not associated with longer mean reaction times on the PVT; $2 b$ : Lower nocturnal sleep time was not associated with higher percent of lapses on the PVT; 2 : : Lower total sleep time was not associated with a higher percent of false starts.

Finally, hypotheses 3a, 3b, and 3c were also not supported; 3a: Higher nocturnal sleep fragmentation was not associated with longer mean reaction times on the PVT; $2 b$ : Higher nocturnal sleep fragmentation was not associated with higher percent of lapses on the PVT; $3 c$ : Higher nocturnal sleep fragmentation was not associated with higher percent of false starts on the PVT.

Results for Research Question 2.

Research Question 2: Is sleep fragmentation or sleep deprivation more strongly associated with functional impairment in postpartum mothers? 
The bivariate correlations above were not statistically significant for any hypothesis; therefore, no partial correlations were calculated. Specifically, there were no significant associations between total sleep time, nocturnal sleep time, and sleep fragmentation with the same performance variable, which means the assessment of difference in associations is unnecessary.

\section{Supplemental Analyses}

Sleep (total sleep time, nocturnal sleep fragmentation, and sleep efficiency) and performance (mean reaction time, percent lapses per trial, and percent false starts) data were collapsed into weekly average values for each participant. Change in sleep and performance measures were examined across postpartum weeks eight through sixteen. Repeated measures analyses of variance were conducted with polynomial significance using linear, quadratic, and cubic trend analyses for unweighted means. Overall, 7.81\% of weekly sleep data were missing; specifically, there were 15 out of 192 weeks of missing data for each sleep variable. Overall, $3.13 \%$ of weekly performance data were missing; specifically, there were 6 out of 192 weeks of missing data for each performance variable. Again, no values were imputed for missing data.

When examining for the presence of associations between sleep and performance measures within each postpartum week all weekly sleep and performance values were checked for normality (skew and kurtosis). Percent false starts were skewed and kurtotic for two of the eight weeks. Percent false starts during those two weeks were logarithmically transformed and bivariate correlations were run on both the raw and logarithmic transformed values within those independent weeks. However, statistical results for the transformed and untransformed values did not differ and therefore results are reported on raw values. 


\section{Change in sleep variables across postpartum weeks 8 through 15.}

Total sleep time met Mauchly's Test of Sphericity $>.05$, but did not change significantly across postpartum weeks $F(7,91)=.70, p=.68, \eta^{2}=.05$ (Figure 1). Also, total sleep time did not change according to a linear, quadratic, or cubic trend; these values are reported in Table 3. Nocturnal sleep time did not meet Mauchly's Test of Sphericity > .05; therefore the Greenhouse-Geisser correction statistic was used for interpretation. Nocturnal sleep time did not change significantly across postpartum weeks $F(3.07,39.93)=.63, p=.73, \eta^{2}=.05$ (Figure 2). Also, nocturnal sleep time did not change according to a linear, quadratic, or cubic trend; these values are reported in Table 4.

Sleep fragmentation did not meet Mauchly's Test of Sphericity > .05; therefore the Greenhouse-Geisser correction statistic was used for interpretation. Sleep fragmentation changed significantly across postpartum weeks $F(3.85,50.01)=2.73, p<.05, \eta^{2}=.17$ (Figure 3 ). Additionally, according to the trend analyses, sleep fragmentation decreased linearly across postpartum weeks $F(1,13)=11.05, p=.005, \eta^{2}=.46$. Sleep fragmentation values for the linear, quadratic, and cubic trend analyses are reported in Table 5.

Sleep efficiency did not met Mauchly's Test of Sphericity > .05; therefore the Greenhouse-Geisser correction statistic was used for interpretation. Sleep efficiency changed significantly across postpartum weeks $F(7,91)=3.46, p=.01, \eta^{2}=.21$ (Figure 4). Additionally, according to the trend analyses sleep efficiency increased linearly across postpartum weeks $F(1$, $13)=12.56, p=.004, \eta^{2}=.49$. Sleep efficiency values for the linear, quadratic, and cubic trend analyses are reported in Table 6 . 
Change in performance variables across postpartum weeks 8 through 15.

Mean reaction time did not meet Mauchly's Test of Sphericity $>.05$; therefore, the Greenhouse-Geisser correction statistic was used for interpretation. Mean reaction time did not change significantly across postpartum weeks $F(2.10,42.02)=.69, p=.68, \eta^{2}=.03$ (Figure 5). Also, mean reaction time did not change according to a linear, quadratic, or cubic trend; these values are reported in Table 7.

Percent lapses per trial did not meet Mauchly's Test of Sphericity > .05; therefore, the Greenhouse-Geisser correction statistic was used for interpretation. Percent lapses per trial did not change significantly across postpartum weeks $F(2.15,42.95)=.78, p=.47, \eta^{2}=.04$ (Figure 6). Also, percent lapses per trial did not change according to a linear, quadratic, or cubic trend; these values are reported in Table 8 .

Percent false starts per trial did not meet Mauchly's Test of Sphericity > .05; therefore, the Greenhouse-Geisser correction statistic was used for interpretation. Percent false starts per trial did not change significantly across postpartum weeks $F(1.40,27.96)=3.02, p=.08, \eta^{2}=.13$ (Figure 7). Also, mean reaction time did not change according to a linear, quadratic, or cubic trend; these values are reported in Table 9.

Associations between sleep and performance measures within each postpartum week Bivariate correlations were conducted for both sleep (total sleep time, sleep fragmentation, and sleep efficiency) and performance (mean reaction time, percent lapses per trial, and percent false starts per trial) variables within each postpartum week (postpartum weeks 8 through 16). All correlation values within weeks eight through sixteen are reported in Tables 10-17 respectively. 
Total sleep time and false starts are significantly associated within postpartum week 10, $r$ $=-.51, p=.02$ (Figure 8 ). As total sleep time decreased the percent of false starts per trial increased. There were no comparisons between total sleep time and sleep fragmentation because they were not significantly associated with the same performance variables within the same week.

\section{Discussion}

The purpose of this study was to examine the relations between sleep disturbance and psychomotor vigilance performance among postpartum women. Specifically, two primary research questions were explored. The first research question examined whether higher indices of sleep disturbance were associated with higher levels of attentional state psychomotor performance as indicated by a PVT. The second research question was to assess whether sleep fragmentation or sleep deprivation were more strongly associated with attentional state psychomotor vigilance performance. The following discussion will address group averages on sleep and performance variables, the statistical findings regarding the research questions and supplemental analyses, and limitations of the study and implications for future work.

\section{Group Averages}

\section{Sleep Time}

Across postpartum weeks 8-16, women had an average total sleep time that translates into 7 hours and 34 minutes of sleep per 24-hour period, and nocturnal sleep time (excluding naps) of roughly 7 hours and 24 minutes. The amount of sleep obtained by this sample of postpartum women is lower than the average sleep needed to avoid neurobehavioral deficits (Van Dongen et al., 2003), but is similar to the average amount of sleep obtained by nonpostpartum women. 
The accumulation of sleep loss is called sleep debt, occurring when lost sleep from previous days build up into a sleep need that is carried over to the following night; sleep debt is relieved by making up the lost sleep time (Harvard Women's Health Watch, 2007). According to a recent study on the dose-response effects of incremental sleep deprivation, Van Dongen and colleagues (2003) revealed that humans need an average of 8 hours and 10 minutes of sleep (objectively measured) per 24-hour period to avoid cumulative neurobehavioral deficits on psychomotor vigilance, digit symbol, and serial addition / subtraction tasks. That is, as sleep time less than 8 hours and 10 minutes accumulates into sleep debt, neurobehavioral deficits increase. Across postpartum weeks 8-16 the average sleep time acquired by our sample of women falls short of the average sleep time needed to avoid neurobehavioral deficits. Neurobehavioral deficits that may occur during postpartum weeks 8-16 could be detrimental to the maternal care given to the infant, as well as the productivity and safety of postpartum women returning to work.

The results from this study suggest that during postpartum weeks 8-16, women obtain similar amounts of sleep as nonpostpartum women of the same age. According to a national poll, 25-34-year-old women spent roughly 7 hours and 51 minutes of time in bed per night (National Sleep Foundation, 2007); however, a measure of time in bed is a proxy for the actual amount of sleep obtained during the time in bed period. In a study by Swain and colleagues (1997) a control group of nonpostpartum women, approximately 31 years of age, reported having slept on average 7 hours and 18 minutes per night. The amount of sleep obtained by our sample of postpartum women may be similar to normative values; however, postpartum sleep is frequently interrupted, or fragmented. 
The nocturnal sleep fragmentation for this sample of postpartum women was objectively explored (Table 1). Previous studies have not reported data that suggest normative values for sleep fragmentation. However, postpartum women report more interruptions during nocturnal sleep than nonpostpartum women (Swain et al., 1997). The change in sleep fragmentation across postpartum weeks 8-16 will be discussed in more detail later in the discussion.

\section{Performance}

Across postpartum weeks 8-16 women demonstrated values on the PVT that were indicative of attentional state psychomotor performance impairment. The average reaction time across postpartum weeks was $401 \mathrm{msec}$. This response time is higher than normative reaction time values for women of approximately 250msec (Blatter, Graw, Munch, Knoblauch, WirzJustice, \& Cajochen, 2006). The normative reaction time value for women in this study was based on a small sample size and standard PVT methodology; however, when directly comparing the current study with these norms, the average response time values was $151 \mathrm{msec}$ higher in the current study. As previously discussed, reaction time on the PVT has been found to increase as a function of sleep loss (Belenky et al., 2003; Pivik, 1991). Overall, the average reaction time value in this sample of postpartum women is higher than normative values for the same demographic.

Additionally, the percent of lapses (16.69\%) and percent of false starts $(2.18 \%)$ per trial in this sample is high. When compared to normative values, there are approximately 1.55 lapses (about 1.58\% lapses per trial) on a 10-minute PVT (Drummond et al., 2005) and .18 false starts (about .30\% false starts per trial) on a 5 minute PVT (Blatter et al., 2006). The PVT used in the study by Drummond and colleagues was an adaptation from standard PVT methodology, such that it was modified for an fMRI scanner. The percent of lapses and false starts are higher in this 
sample of postpartum women than normative values (15.11\% and $1.88 \%$ higher respectively); this may be attributed to disturbed sleep as discussed below.

Sleep and Psychomotor Performance Variables

The first research question assessed whether higher indices of sleep disturbance were associated with higher levels of functional impairment. The intracorrelations within sleep and psychomotor performance variables will be discussed followed by a discussion of the intercorrelations between sleep and psychomotor performance variables.

Intracorrelations within sleep and psychomotor performance variables.

No significant associations were found between sleep time and sleep fragmentation. This lack of significant association could mean that sleep obtained by this sample was fragmented regardless of how long they slept.

As expected, total sleep time and nocturnal sleep time were significantly correlated. The difference between these variables was the presence or absence of naps in their totals. Within this sample naps were not frequently taken; therefore, these variables total sleep time and nocturnal sleep time remained similar.

No significant associations were found between percent lapses and percent false starts. Within this sample, lapses and false starts may measure different kinds of performance impairment; however, this conclusion requires further examination. Both percent lapses and percent false starts per trial were significantly associated with mean reaction time. As expected, more lapses within a trial increased the value for mean reaction time. Unexpectedly, as the percent of false starts per trial increased, mean reaction time decreased. Both false starts and mean reaction time are measures of performance impairment and were therefore expected to be positively correlated. However, these results suggest that women who responded faster to the 
PVT were also more likely to respond prematurely. The reason for this association could be that when women were more vigilant they were also more impulsive, alternatively false starts could be interpreted as a compensatory mechanism for impairment; however, these are matters of speculation.

Intercorrelations between sleep and psychomotor performance variables.

The lack of significant associations between sleep and performance variables may have been due to the dependency of the sleep data; that is, the adverse effects of sleep disturbance can be carried over time. Correlations were conducted between sleep and performance values from the following morning, whereas the amount and quality of sleep from several nights prior may have had an effect on psychomotor performance.

The second research question was intended to examine whether sleep fragmentation or sleep deprivation was more strongly associated with attentional-based psychomotor vigilance performance. As previously discussed, since total sleep time and sleep fragmentation were not associated with the same performance variables, this research question was not examined. Change in sleep and psychomotor performance variables

The changes in sleep and performance variables were assessed across postpartum weeks 8-16. Since sleep variables changed over this time, the associations between sleep and performance variables were analyzed within each postpartum week.

\section{Change in sleep variables.}

Total sleep time, nocturnal sleep time, sleep fragmentation, and sleep efficiency were assessed for change over time. The interpretation of these variables will be discussed concurrently. Total sleep time and nocturnal sleep time did not significantly change over time, nor did they demonstrate a significant trend. However, both sleep fragmentation and sleep 
efficiency changed significantly and demonstrated linear trends. Specifically, sleep

fragmentation significantly decreased and sleep efficiency significantly increased across weeks. As described above, sleep fragmentation and sleep efficiency calculations are opposite measures of an observed sleep period; therefore, as participant sleep became less fragmented their sleep became more efficient. The linear trend indicates that these variables consistently change in the same directions across the postpartum weeks studied. The linear trend also suggests that these variables may have been changing before and after the 8 week study.

Results suggest that sleep fragmentation decreased while sleep time remained the same across weeks 8-16. Together, across postpartum weeks 8-16 the amount of sleep obtained remained the same; however, across time it was obtained in more consolidated periods. Sleep fragmentation may have decreased across time because infant nocturnal signaling decreased. Additionally, sleep fragmentation may have decreased across time because of maternal physiological alterations after birth. Furthermore, sleep time did not increase across time potentially because mothers felt they were getting better sleep due to the decrease in sleep fragmentation. These interpretations are entirely speculative as variables that would provide a mechanistic explanation of sleep fragmentation and sleep time were not taken into account within the current study.

\section{Change in psychomotor performance variables.}

Mean reaction time, percent lapses per trial, and percent false starts per trial were assessed for change over time. None of the performance variables changed significantly or demonstrated a trend across postpartum weeks 8-16. Results suggest that attentional state psychomotor performance remains relatively poor across postpartum weeks 8-16. 
The variables derived from the PVT have ecological validity when applied to the lives of new mothers. As reviewed by Dorrian and colleagues, the PVT cannot be directly extrapolated to everyday tasks, but it does tap fundamental properties to many of these tasks, that is, attention and rapid response (Dorrian, Rogers, \& Dinges, 2005). Furthermore, these researchers successfully draw a close parallel between the results from the PVT to driving performance, primarily due to of the necessity to sustain attention and respond quickly during driving. Driving may be considered an everyday task for postpartum women, additionally during postpartum weeks 8-16 women are expected to return to work and carry out their work related responsibilities. The results from the current study indicate that new moms may be susceptible to impaired driving and impairment during work and other everyday tasks that require attention and rapid response.

Associations between sleep and performance measures.

Sleep and performance variables were analyzed for associations within each postpartum week. The only significant association between variables was between total sleep time and percent of false starts per trial within postpartum week 10. The direction of association was as expected; as total sleep time increased the number of false starts decreased. These findings should be interpreted with caution because if there is in fact an association between sleep time and false starts we would expect to see the association across all postpartum weeks, not exclusively during a single postpartum week.

\section{Limitations and Future Directions}

Limitations within the study may have influence the results for the hypotheses and the supplemental analyses. For example, the PVT may not have been administered properly by our sample of postpartum women in the field setting (e.g. multitasking during test). However, as the 
study was conducted in the field, higher experimental-control was sacrificed for higher generalizability, which is a strength to this study.

Another limitation is that the choice of PVT variables may also have been inappropriate for this sample. The parameters set by the researchers regarding extreme reaction time scores may have been too stringent and therefore could have excluded important variance. Other performance variables derived from the PVT may be better suited for detecting variations in performance levels of postpartum women; for example, the lapse domain (longest $10 \%$ of reaction times in a trial), the optimum response domain (fastest $10 \%$ of reaction times in a trial), or the median response time (Loh et al., 2004). Alternative performance variables to those assessed in this study will be examined further in future analyses.

Future research will involve further examination of the dataset. Additional variables collected from the larger study and other statistical techniques will be used to further explore sleep and performance data. For example, subjective ratings of sleepiness and fatigue may mediate the associations between objective measures of sleep and performance variables. Furthermore, growth curve analyses could be used to assess intraindividual change in sleep and performance across postpartum weeks 8-16.

The associations between sleep and performance variables may be more pronounced earlier in the postpartum period and a larger sample would help detect smaller associations and differences across time. Data is currently being collected from postpartum week 1 through postpartum week 12 and we plan to collect a large sample size. The findings and limitations of our study are intended to advance the scientific understanding of sleep and attentional state psychomotor performance in postpartum women. 


\section{Conclusion}

Due to the high prevalence of sleep disturbance in postpartum women and its adverse effects on health, mood, and performance, there is a critical need to better understand the specific form of sleep disturbance in these women. The current study provides objective data regarding the amount of sleep fragmentation in postpartum women and describes how it changes across postpartum weeks 8-16. Additionally, this study indicates that postpartum women perform poorly on the PVT, yet they obtain a reasonable amount of sleep time. The poor attentional state psychomotor performance values of these women may be due to sleep fragmentation; however, data from this study do not suggest that sleep and these performance values are associated. The effect of sleep fragmentation and the reason for poor psychomotor performance in this sample of postpartum women remains unknown. During the 8-16 week postpartum period women are expected to return to work; however, their sleep fragmentation values are still decreasing and their attentional state psychomotor performance values are poor. 


\section{References}

Acebo, C., \& LeBourgeois, M. K. (2006). Actigraphy. Respiratory Care Clinics of North America, 12, 23-30.

Armstrong, K. L., Van Haeringen, A. R., Dadds, M. R., \& Cash, R. (1998). Sleep Deprivation or Postnatal Depression in Later Infancy: Separating the chicken from the egg. Journal of Pediatrics and Child Health, 34, 260-262.

Barrett, L. F., \& Barrett, D. J. (2001). An introduction to computerized experience sampling in psychology. Social Science Computer Review, 19, 175-185.

Belenky, G., Wesensten, N. J., Thorne, D. R., Thomas, M. L., Sing, H. C., Redmond, D. P., et al. (2003). Patterns of performance degradation and restoration during sleep restriction and subsequent recovery: a sleep dose-response study. Journal of Sleep Research, 12, 1-12.

Blatter, K., Graw, P., Munch, M., Knoblauch, W., \& Cajochen, C. (2006). Gender and age differences in psychomotor vigilance performance under differential sleep pressure conditions. Behavioural Brain Research, 168, 312-317.

Bonnet, M. H. (1985). Effect of sleep disruption on sleep, performance, and mood. Sleep, 8, 11 19.

Bonnet, M. H. (1986). Performance and sleepiness as a function of frequency and placement of sleep disruption. Psychophysiology, 23, 263-271.

Bonnet, M. H. (2005a). Acute sleep deprivation. In M. H. Kryger, T. Roth, \& W. C. Dement (Eds.), Principles and Practice of Sleep Medicine (4 ${ }^{\text {th }}$ ed., pp. 51-66). Philadelphia, PA: Elsevier Saunders. 
Bonnet, M. H. (2005b). Sleep fragmentation. In. C. A. Kushida (Ed.), Lung biology in health and disease: Vol. 192, pp. 103-120, Sleep deprivation: Basic Science, Physiology, and Behavior. New York, NY: Marcel Dekker.

Bonnet, M. H., \& Arand, D. L. (2003). Clinical effects of sleep fragmentation versus sleep deprivation. Sleep Medicine Reviews, 7, 297-310.

Dennis, C. L. \& Ross, L. (2005). Relationships among infant sleep patterns, maternal fatigue and development of depressive symptomology. Birth, 32, 187-193.

DeLeon, C. W. \& Karraker, K. H. (2007). Intrinsic and extrinsic factors associated with night waking in 9-month-old infants. Infant behavior and development, 30, 596-605.

de Souza, L., Benedito-Silva, A.A., Pires, M.L., Povares, D., Tufik, S., \& Calil, H.M. (2003). Further validation of actigraphy for sleep studies. Sleep, 26, 81-85.

Dinges, D. F., \& Kribbs, N. B. (1991). Performing while sleepy: effects of experimentally induced sleepiness. In T. H. Monk (Ed.) Sleep, Sleepiness, and Performance (pp. 97 128). New York, NY: Wiley.

Dinges, D. F., Pack, F., Williams, K., Gillen, K. A., Powell, J. W., Ott, G. E., et al. (1997). Cumulative sleepiness, mood disturbance, and psychomotor vigilance performance decrements during a week of sleep restricted to 4-5 hours per night. Sleep 20, 267-277.

Dinges, D. F., \& Powell, J. W. (1985). Micorcomputer analyses of performance on a portable, simple visual RT task during sustained operations. Behavior Research Methods, Instruments, \& Computers, 17, 652-655.

Dinges, D. F., Rogers, N. L., \& Baynard, M. D. (2005). Chronic Sleep Deprivation. . In M. H. Kryger, T. Roth, \& W. C. Dement (Eds.), Principles and Practice of Sleep Medicine $\left(4^{\text {th }}\right.$ ed., pp. 67-76). Philadelphia, PA: Elsevier Saunders. 
Dorrian, J., Rogers, N., \& Dinges, D. (2005). Psychomotor vigilance performance:

Neurocognitive assay sensitive to sleep loss. In C. A. Kushida (Ed). Sleep Deprivation: Clinical Issues, Pharmacology, and Sleep Loss Effects (pp. 39-70). New York, NY: Marcel Dekker.

Drummond, S. P., Bischoff-Grethe, A., Dinges, D.F., Ayalon, L., Mednick, S. C., \& Meloy, M. J. (2005). The neural basis of the psychomotor vigilance task. Sleep, 28,1059-1068.

Drummond, S. P., \& Orff, M. A. (2005). Sleep Deprivation/Restriction: Human Studies. In M. R. Opp (Ed), SRS Basics of Sleep Guide (pp. 39-43). Westchester, Illinois: Sleep Research Society.

Durmer, J. S., \& Dinges, D. F. (2005). Neurocognitive consequences of sleep deprivation. Seminars in neurology, 25, 117-129.

Ferrara, M., De Gennaro, L. (2002). How much sleep do we need? Sleep Medicine Reviews, 5, 155-179.

Franken, P. (2002). Long-term vs. short-term processes regulating REM sleep. Journal of sleep research, 11, 17-28.

Gay, C.L., Lee, K.A., \& Lee, S.Y., (2004). Sleep patterns and fatigue in new mothers and fathers. Biological Research for Nursing, 5, 311-318.

Gaylor, E., \& Manber, R. (2005). Pregnancy and postpartum. In C. A. Kushida (Ed.) Lung biology in health and disease: Vol. 193, pp. 177-194, Sleep deprivation: Clinical Issues, Pharmacology, and Sleep Loss Effects. New York, NY: Marcel Dekker. 
Harvard Womens Health Watch (2007). Repaying your sleep debt. If sleep were a credit card company, many of us would be in deep trouble. Retrieved February 10, 2008, from Harvard Medical School Web site: http://www.patienteducationcenter.com/aspx/ HealthELibrary/HealthETopic.aspx?cid=W0707a

Hisock, H. \& Wake, M. (2001). Infant sleep problems and postnatal depression: A community based sample. Pediatrics, 107, 1317-1322.

Hisock, H. \& Wake, M. (2002). Randomised controlled trial of behavioural infant sleep intervention to improve infant sleep and maternal mood. British Medical Journal, 324, 1062-1067.

Howell, D. C. (2002). Statistical methods for psychology ( $5^{\text {th }}$ ed.). Belmont, CA: Duxbury Press. Jean-Louis, G., von Gizycki, H., Zizi, F., Fookson, J., Spielman, A., Nunes, J., Fullilove, R., \& Taub, H. (1996). Determination of sleep and wakefulness with the actigraph data analysis software (ADAS). Sleep, 19, 739-743.

Jenni, O. G., \& Carskadon, M. A. (2005). Sleep Deprivation/Restriction: Human Studies. In M. R. Opp (Ed), SRS Basics of Sleep Guide (pp. 11-19). Westchester, Illinois: Sleep Research Society.

Karraker, K. H. \& Young, M. (2007). Night waking in 6-month-old infants and maternal depressive symptoms. Journal of applied developmental psychology, 28, 493-498.

Kang, M. J., Matsumoto, K., Shinkoda, H., Mishima, M., \& Seo, Y. J. (2002). Longitudinal Study for Sleep-Wake Behaviours of Mothers from Pre-Partum to Post-Partum Using Actigraph and Sleep Logs. Psychiatry and Clinical Neurosciences, 56, 251-252. 
Karacan, I., Williams, R. L., Hursch, C. J., McCaulley, M., Heine, M. W. (1969). Some implications of the sleep aptterns of pregnancy for postpartum emotional disturbances. The British Journal of Psychiatry, 115, 929-935.

Kushida, C.A., Chang, A., Gadkary, C., Guilleminault, C., Carrillo, O., \& Dement, W.C. (2001). Comparison of actigraphic, polysomnographic, and subjective assessment of sleep parameters in sleep-disordered patients. Sleep Medicine, 2, 389-396.

Landis, C. A. (2005). Partial and sleep-state selective deprivation. In. C. A. Kushida (Ed.), Lung biology in health and disease: Vol. 192 Sleep deprivation. New York, NY: Marcel Dekker.

Lee, K. A., McEnany, G., \& Zaffke, M. E. (2000). REM sleep and mood state in childbearing women: sleepy or weepy? Sleep, 23, 1-9.

Levine, B., Roehrs, T., Stepanski, E., Zorick, F., \& Roth, T. (1987). Fragmenting sleep diminishes its recuperative value. Sleep, 10, 590-599.

Loh, S., Lamond, N., Dorrian, J., Roach, G., \& Dawson, D. (2004). The validity of psychomotor vigilance tasks of less than 10-minute duration. Behavior Research Methods, Instruments, \& Computers, 36, 339-346.

Manber, R. \& Armitage, R. (1999). Sex, Steroids, and Sleep: A Review. Sleep, 22, 540-555.

Martin, S. E., Engleman, H. M., Deary, I. J., \& Douglas, N. J. (1996). The effect of sleep fragmentation on daytime function. American Journal of Respiratory and Critical Care Medicine, 153, 1328-1332.

Montgomery-Downs, H. E., \& Gozal, D. (2006). Sleep habits and risk factors for sleep disordered breathing in infants and young toddlers in Louisville, Kentucky. Sleep Medicine, 7, 211-219. 
Motivala, S. H., \& Irwin, M. R. (2007). Sleep and immunity: Cytokine pathways linking sleep and health outcomes. Current Directions in Psychological Science, 16, 21-25.

Murray, L., Cooper, P., \& Hipwell, A. (2003). Mental health of parents caring for infants. Archives of Women's Mental Health, 6, 71-77.

National Sleep Foundation. (2007). 2007 Sleep in America poll. Washington, DC. (available at http://www.sleepfoundation.org/).

Nishihara, K., Horiuchi, S., Eto, H., \& Uchida, S. (2001). Comparisons of sleep patterns between mothers in post-partum from 9 to 12 weeks and non-pregnant women. Psychiatry and Clinical Neurosciences, 55, 227-228.

Nishihara, K., Horiuchi, S., Eto, H., \& Uchida, S. (2000). Mothers’ wakefulness at night in the post-partum period is related to their infants' circadian sleep-wake rhythm. Psychiatry and Clinical Neurosciences, 54, 305-306.

Ohayon, M. M., Carskadon, M. A., Guilleminault, C., \& Vitiello, M. V. (2004). Meta-analysis of quantitative sleep parameters from childhood to old age in healthy individuals: Developing normative sleep values across the human lifespan. Sleep, 27, 1255-1273.

Paulson, J. F., Dauber, S., Leiferman, J. A. (2006). Individual and combined effects of postpartum depression in mothers and fathers on parenting behavior. Pediatrics, 118, 659-668.

Peirano, P., Algarin, C., \& Uauy, R. (2003). Sleep-wake states and their regulatory mechanisms throughout early human development. The Journal of Pediatrics, 143, 70-79.

Pilcher, J. J., \& Huffcutt, A. I. (1996). Effects of sleep deprivation on performance: A meta analysis. Sleep, 19, 318-326. 
Pivik, R. T. (1991). The several qualities of sleepiness: psychophysiological considerations. In T. H. Monk (Ed.), Sleep, Sleepiness, and Performance (pp. 3-37). New York, NY: Wiley.

Radloff, L. A. (1977). The CES-D scale: A self-report depression scale for research in the general population. Applied Psychological Measurement, 1, 385-401.

Ratcliff, R. (1993). Methods for dealing with reaction time outliers. Psychological Bulletin, 114, 510-532.

Rechtschaffen, A., Bergmann, B. M., Everson, C. A., Kushida, C. A., \& Gilliland, M. A. (1989). Sleep deprivation in the rat: X. integration and discussion of the findings. Sleep, 12, 6887.

Righetti-Veltema, M., Conne-Perreard, E., Bousquet, A., \& Manzano, J. (2002). Postpartum depression and mother-infant relationship at 3 months old. Journal of Affective Disorders, 70, 291-306.

Ross, L. E. Murray, B. J., \& Steiner, M. (2005). Sleep and perinatal mood disorders: a critical review. Journal of Psychiatry and Neuroscience, 30, 247-256.

Sadeh, A., \& Acebo, C. (2003). The role of actigraphy in sleep medicine. Sleep Medicine Reviews, 6, 113-124.

Santiago, J. R., Nolledo, M. S., Kinzler, W., Santiago, T. V. (2001). Sleep and sleep disorders in pregnancy. Annals of Internal Medicine, 134, 396-408.

Sheldon, S. H. (2005). Anatomy of Sleep. In. S. H. Sheldon, R. Ferber, M. H. Kryger (Eds.), Principles and Practice of Pediatric Sleep Medicine (pp. 35-41). Elsevier Saunders.

Shinkoda, H., Matsumoto, K., \& Park, Y. M. (1999). Changes in sleep-wake cycle during the period from late pregnancy to puerperium identified through the wrist actigraph and sleep logs. Psychiatry and Clinical Neurosciences, 53, 133-135. 
Singh, M., Drake, C. L., Roehrs, T., Hudgel, D. W., \& Roth, T. (2005). The association between obesity and short sleep duration: a population-based study. Journal of clinical Sleep Medicine, 1, 357-363.

Spath-Schwalbe, E., Gofferje, M., Kern, W., Born, J., Fehm, H. L. (1991). Sleep disruption alters nocturnal ACTH and cortisol secretory patterns. Biological Psychiatry, 29, 575-584.

Spiegel, K., Knutson, K., Leproult, R., Tasali, E., \& Van Cauter, E. (2005). Sleep loss: a novel risk factor for insulin resistance and Type 2 diabetes. Journal of Applied Physiology, 99, 2008-2019.

Spiegel, K., Sheridan, J. F., Van Cauter, E. (2002). Journal of the American Medical Association, 288, 1471-1472.

Stepanski, E. J. (2002). The effect of sleep fragmentation on daytime function. Sleep, 25, 268276.

Stepanski, E., Lamphere, J., Badia, P., Zorick, G., \& Roth, T. (1984). Sleep fragmentation and daytime sleepiness. Sleep, 7, 18-26.

Stone, A. A., Shiffman, S., Schwartz, J. E., Broderick, J. E., \& Hufford, M. R. (2002). Paatient non-compliance with paper diaries. British Medical Journal, 324, 1193-1194.

Swain, A. M., O’Hara, M. W., Starr, K. R., \& Gorman, L. L. (1997). A prospective study of sleep, mood, and cognitive function in postpartum and nonpostpartum women. Obstetrics and Gynecology, 90, 381-386.

Taheri, S., Lin, l., Austin, D., Young, T., \& Mignot, E. (2004). Short sleep duration is associated with reduced leptin, elevated ghrelin, and increased body mass index. Public Library of Science, $210-217$. 
Tamakoshi, A., Ohno, Y. (2004). Self-reported sleep duration as a predictor of all-cause mortality: Results from the JACC study, Japan. Sleep, 27, 51-54.

Thorne, D. R., Johnson, D. E., Redmond, D. P., Sing, H. C., \& Belenky, G. (2005). The Walter Reed palm-held psychomotor vigilance test. Behavior Research Methods, 37, 111-118.

Van Donge, H. P., Maislin, G., Mullington, J. M., \& Dinges, D. F. (2003). The cumulative cost of additional wakefulness: dose-response effects on neurobehavioral functions and sleep physiology from chronic sleep restriction and total sleep deprivation. Sleep, 26, 117-126.

Warren, S. L., Howe, G., Simmens, S. J., \& Dahl, R. E. (2006). Maternal depressive symptoms and child sleep: models of mutual influence over time. Developmental psychopathology, 18, 1-16.

Wolfson, A. R., \& Lee, K. A. (2005). Pregnancy and the postpartum period. In M. H. Kryger, T. Roth, \& W. C. Dement (Eds.), Principles and Practice of Sleep Medicine ( $4^{\text {th }}$ ed., pp. 1278-1286). Philadelphia, PA: Elsevier Saunders. 
Table 1

Descriptive Statistics for Sleep and Performance Variables

\begin{tabular}{|c|c|c|c|c|c|}
\hline & $M$ & $S D$ & $S E$ & Skew & Kurtosis \\
\hline $\begin{array}{l}24 \text { Hour } \\
\text { Total Sleep } \\
\text { Time (min.) }\end{array}$ & 454.49 & 38.03 & 7.76 & .50 & -.07 \\
\hline $\begin{array}{l}\text { Nocturnal } \\
\text { Sleep Time } \\
\text { (min.) }\end{array}$ & 444.22 & 37.68 & 7.69 & .26 & .15 \\
\hline $\begin{array}{l}\text { Sleep } \\
\text { Fragmentation } \\
(\%)\end{array}$ & 14.23 & 3.31 & .68 & -.19 & .22 \\
\hline $\begin{array}{l}\text { Mean } \\
\text { Reaction } \\
\text { Time (msec.) }\end{array}$ & 401.51 & 64.50 & 13.17 & .13 & -1.01 \\
\hline $\begin{array}{l}\text { Percent } \\
\text { Lapses } \\
\text { Per Trial }\end{array}$ & 16.69 & 11.60 & 2.37 & .53 & -.98 \\
\hline $\begin{array}{l}\text { Percent } \\
\text { False Starts } \\
\text { Per Trial }\end{array}$ & 2.18 & 2.75 & .56 & 2.56 & 6.99 \\
\hline
\end{tabular}

* Represents values with high skew (>3)

** Represents values with high kurtosis $(>10)$ 
Table 2

Intercorrelations Between Sleep and Performance Variables

\begin{tabular}{|c|c|c|c|c|c|c|}
\hline & 1 & 2 & 3 & 4 & 5 & 6 \\
\hline $\begin{array}{l}\text { 1. } 24 \text { Hour Total } \\
\text { Sleep Time }\end{array}$ & - & $.94^{* *}$ & .00 & -.01 & -.08 & -.16 \\
\hline $\begin{array}{l}\text { 2. Nocturnal } \\
\text { Sleep Time }\end{array}$ & & - & .03 & -.10 & -.17 & -.17 \\
\hline $\begin{array}{l}\text { 3. Sleep } \\
\text { Fragmentation }\end{array}$ & & & - & -.06 & .06 & .14 \\
\hline $\begin{array}{l}\text { 4. Mean Reaction } \\
\text { Time }\end{array}$ & & & & - & $.97 * *$ & -.26 \\
\hline $\begin{array}{l}\text { 5. Percent Lapses } \\
\text { Per Trial }\end{array}$ & & & & & - & -.14 \\
\hline $\begin{array}{l}\text { 6. Percent False } \\
\text { Starts Per Trial }\end{array}$ & & & & & & - \\
\hline
\end{tabular}

${ }^{*} p<.05$ (two-tailed), ${ }^{* *} p<.001$ (two-tailed) 
Table 3

24 HourTotal Sleep Time Values for Unweighted Linear, Quadratic and Cubic Trend Analyses

\begin{tabular}{|c|c|c|c|c|c|c|}
\hline \multirow[b]{2}{*}{$\begin{array}{l}\text { Postpartum } \\
\text { Week }\end{array}$} & \multicolumn{3}{|c|}{$F(d f)$} & \multicolumn{3}{|c|}{ Descriptives } \\
\hline & Linear & Quadratic & Cubic & $N$ & $M$ & $S E$ \\
\hline Total & $.20(1,13)$ & $.49(1,13)$ & $1.75(1,13)$ & 192 & 455.93 & 3.37 \\
\hline Eight & & & & 14 & 457.51 & 11.59 \\
\hline Nine & & & & 14 & 465.45 & 14.54 \\
\hline Ten & & & & 14 & 472.55 & 11.71 \\
\hline Eleven & & & & 14 & 465.68 & 12.80 \\
\hline Twelve & & & & 14 & 463.75 & 11.49 \\
\hline Thirteen & & & & 14 & 452.08 & 13.84 \\
\hline Fourteen & & & & 14 & 467.08 & 11.40 \\
\hline Fifteen & & & & 14 & 459.43 & 13.19 \\
\hline
\end{tabular}


Table 4

Nocturnal Sleep Time Values for Unweighted Linear, Quadratic and Cubic Trend Analyses

\begin{tabular}{|c|c|c|c|c|c|c|}
\hline \multirow[b]{2}{*}{$\begin{array}{l}\text { Postpartum } \\
\text { Week }\end{array}$} & \multicolumn{3}{|c|}{$F(d f)$} & \multicolumn{3}{|c|}{ Descriptives } \\
\hline & Linear & Quadratic & Cubic & $N$ & $M$ & $S E$ \\
\hline Total & $.39(1,13)$ & $.62(1,13)$ & $1.86(1,13)$ & 192 & 446.67 & 2.18 \\
\hline Eight & & & & 14 & 443.07 & 11.58 \\
\hline Nine & & & & 14 & 454.46 & 12.42 \\
\hline Ten & & & & 14 & 458.16 & 11.97 \\
\hline Eleven & & & & 14 & 455.40 & 10.31 \\
\hline Twelve & & & & 14 & 458.09 & 10.83 \\
\hline Thirteen & & & & 14 & 444.93 & 12.24 \\
\hline Fourteen & & & & 14 & 457.67 & 11.43 \\
\hline Fifteen & & & & 14 & 453.46 & 13.29 \\
\hline
\end{tabular}


Table 5

Sleep Fragmentation Values for Unweighted Linear, Quadratic and Cubic Trend Analyses

\begin{tabular}{|c|c|c|c|c|c|c|}
\hline \multirow[b]{2}{*}{$\begin{array}{l}\text { Postpartum } \\
\text { Week }\end{array}$} & \multicolumn{3}{|c|}{$F(d f)$} & \multicolumn{3}{|c|}{ Descriptives } \\
\hline & Linear & Quadratic & Cubic & $N$ & $M$ & $S E$ \\
\hline Total & $11.05(1,13)^{* *}$ & $.38(1,13)$ & $.34(1,13)$ & 192 & 14.25 & .30 \\
\hline Eight & & & & 14 & 15.01 & 1.31 \\
\hline Nine & & & & 14 & 15.11 & 1.16 \\
\hline Ten & & & & 14 & 13.63 & 1.46 \\
\hline Eleven & & & & 14 & 14.09 & 1.17 \\
\hline Twelve & & & & 14 & 13.79 & 1.16 \\
\hline Thirteen & & & & 14 & 12.66 & .82 \\
\hline Fourteen & & & & 14 & 12.74 & .95 \\
\hline Fifteen & & & & 14 & 12.99 & .79 \\
\hline
\end{tabular}

$* * p=.005$ (two-tailed) 
Table 6

Sleep Efficiency Values for Unweighted Linear, Quadratic and Cubic Trend Analyses

\begin{tabular}{|c|c|c|c|c|c|c|}
\hline \multirow[b]{2}{*}{$\begin{array}{l}\text { Postpartum } \\
\text { Week }\end{array}$} & \multicolumn{3}{|c|}{$F(d f)$} & \multicolumn{3}{|c|}{ Descriptives } \\
\hline & Linear & Quadratic & Cubic & $N$ & $M$ & $S E$ \\
\hline Total & $12.56(1,13)^{* *}$ & $.24(1,13)$ & $2.51(1,13)$ & 192 & 88.71 & .29 \\
\hline Eight & & & & 14 & 88.39 & 1.15 \\
\hline Nine & & & & 14 & 87.47 & 1.01 \\
\hline Ten & & & & 14 & 88.86 & 1.21 \\
\hline Eleven & & & & 14 & 89.05 & 1.10 \\
\hline Twelve & & & & 14 & 89.43 & .97 \\
\hline Thirteen & & & & 14 & 90.38 & .78 \\
\hline Fourteen & & & & 14 & 90.49 & .83 \\
\hline Fifteen & & & & 14 & 90.03 & .84 \\
\hline
\end{tabular}

${ }^{* *} p=.004$ (two-tailed) 
Table 7

Mean Reaction Time Values for Unweighted Linear, Quadratic and Cubic Trend Analyses

\begin{tabular}{|c|c|c|c|c|c|c|}
\hline \multirow[b]{2}{*}{$\begin{array}{l}\text { Postpartum } \\
\text { Week }\end{array}$} & \multicolumn{3}{|c|}{$F(d f)$} & \multicolumn{3}{|c|}{ Descriptives } \\
\hline & Linear & Quadratic & Cubic & $N$ & $M$ & $S E$ \\
\hline Total & $.43(1,20)$ & $.39(1,20)$ & $2.27(1,20)$ & 192 & 399.55 & 5.52 \\
\hline Eight & & & & 21 & 402.09 & 21.55 \\
\hline Nine & & & & 21 & 380.92 & 13.81 \\
\hline Ten & & & & 21 & 387.58 & 16.98 \\
\hline Eleven & & & & 21 & 388.75 & 15.80 \\
\hline Twelve & & & & 21 & 399.12 & 16.89 \\
\hline Thirteen & & & & 21 & 397.44 & 16.04 \\
\hline Fourteen & & & & 21 & 404.83 & 15.96 \\
\hline Fifteen & & & & 21 & 400.65 & 16.13 \\
\hline
\end{tabular}


Table 8

Percent Lapse Values for Unweighted Linear, Quadratic and Cubic Trend Analyses

\begin{tabular}{|c|c|c|c|c|c|c|}
\hline \multirow[b]{2}{*}{$\begin{array}{l}\text { Postpartum } \\
\text { Week }\end{array}$} & \multicolumn{3}{|c|}{$F(d f)$} & \multicolumn{3}{|c|}{ Descriptives } \\
\hline & Linear & Quadratic & Cubic & $N$ & $M$ & $S E$ \\
\hline Total & $1.40(1,20)$ & $.05(1,20)$ & $.48(1,20)$ & 192 & 16.23 & 1.04 \\
\hline Eight & & & & 21 & 14.89 & 4.14 \\
\hline Nine & & & & 21 & 12.10 & 2.22 \\
\hline Ten & & & & 21 & 14.17 & 2.99 \\
\hline Eleven & & & & 21 & 15.61 & 3.01 \\
\hline Twelve & & & & 21 & 15.95 & 2.86 \\
\hline Thirteen & & & & 21 & 16.58 & 3.05 \\
\hline Fourteen & & & & 21 & 17.58 & 3.02 \\
\hline Fifteen & & & & 21 & 17.78 & 3.18 \\
\hline
\end{tabular}


Table 9

Percent False Start Values for Unweighted Linear, Quadratic and Cubic Trend Analyses

\begin{tabular}{|c|c|c|c|c|c|c|}
\hline \multirow[b]{2}{*}{$\begin{array}{l}\text { Postpartum } \\
\text { Week }\end{array}$} & \multicolumn{3}{|c|}{$F(d f)$} & \multicolumn{3}{|c|}{ Descriptives } \\
\hline & Linear & Quadratic & Cubic & $N$ & $M$ & $S E$ \\
\hline Total & $3.35(1,20)$ & $1.83(1,20)$ & $1.79(1,20)$ & 192 & 2.18 & .25 \\
\hline Eight & & & & 21 & 1.00 & .23 \\
\hline Nine & & & & 21 & 1.39 & .30 \\
\hline Ten & & & & 21 & 1.56 & .34 \\
\hline Eleven & & & & 21 & 2.18 & .64 \\
\hline Twelve & & & & 21 & 2.15 & .86 \\
\hline Thirteen & & & & 21 & 2.93 & .96 \\
\hline Fourteen & & & & 21 & 3.28 & 1.20 \\
\hline Fifteen & & & & 21 & 2.60 & 1.00 \\
\hline
\end{tabular}


Table 10

Intercorrelations Between Sleep and Performance Variables: Week Eight Postpartum

\begin{tabular}{|c|c|c|c|c|c|c|}
\hline & 1 & 2 & 3 & 4 & 5 & 6 \\
\hline $\begin{array}{l}\text { 1. Total } \\
\text { Sleep Time }\end{array}$ & - & .26 & -.18 & .11 & -.00 & -.14 \\
\hline $\begin{array}{l}\text { 2. Sleep } \\
\text { Fragmentation }\end{array}$ & & - & $-.96 * *$ & .22 & .21 & .05 \\
\hline $\begin{array}{l}\text { 3. Sleep } \\
\text { Efficiency }\end{array}$ & & & - & -.24 & -.27 & -.12 \\
\hline $\begin{array}{l}\text { 4. Mean Reaction } \\
\text { Time }\end{array}$ & & & & - & $.93 * *$ & .20 \\
\hline $\begin{array}{l}\text { 5. Percent Lapses } \\
\text { Per Trial }\end{array}$ & & & & & - & .35 \\
\hline $\begin{array}{l}\text { 6. Percent False } \\
\text { Starts Per Trial }\end{array}$ & & & & & & - \\
\hline
\end{tabular}


Table 11

Intercorrelations Between Sleep and Performance Variables: Week Nine Postpartum

\begin{tabular}{|c|c|c|c|c|c|c|}
\hline & 1 & 2 & 3 & 4 & 5 & 6 \\
\hline $\begin{array}{l}\text { 1. Total } \\
\text { Sleep Time }\end{array}$ & - & -.03 & .08 & -.04 & -.10 & -.32 \\
\hline $\begin{array}{l}\text { 2. Sleep } \\
\text { Fragmentation }\end{array}$ & & - & $-.90 * *$ & .03 & .13 & .28 \\
\hline $\begin{array}{l}\text { 3. Sleep } \\
\text { Efficiency }\end{array}$ & & & - & .10 & .04 & -.21 \\
\hline $\begin{array}{l}\text { 4. Mean Reaction } \\
\text { Time }\end{array}$ & & & & - & $.96 * *$ & -.13 \\
\hline $\begin{array}{l}\text { 5. Percent Lapses } \\
\text { Per Trial }\end{array}$ & & & & & - & -.00 \\
\hline $\begin{array}{l}\text { 6. Percent False } \\
\text { Starts Per Trial }\end{array}$ & & & & & & - \\
\hline
\end{tabular}

${ }^{* *} p<.001$ (two-tailed) 
Table 12

Intercorrelations Between Sleep and Performance Variables: Week Ten Postpartum

\begin{tabular}{|c|c|c|c|c|c|c|}
\hline & 1 & 2 & 3 & 4 & 5 & 6 \\
\hline $\begin{array}{l}\text { 1. Total } \\
\text { Sleep Time }\end{array}$ & - & .06 & .02 & .31 & .25 & $-.51 *$ \\
\hline $\begin{array}{l}\text { 2. Sleep } \\
\text { Fragmentation }\end{array}$ & & - & $-.92 * *$ & .03 & .15 & .09 \\
\hline $\begin{array}{l}\text { 3. Sleep } \\
\text { Efficiency }\end{array}$ & & & - & .02 & -.12 & -.10 \\
\hline $\begin{array}{l}\text { 4. Mean Reaction } \\
\text { Time }\end{array}$ & & & & - & $.97 * *$ & .08 \\
\hline $\begin{array}{l}\text { 5. Percent Lapses } \\
\text { Per Trial }\end{array}$ & & & & & - & -.02 \\
\hline $\begin{array}{l}\text { 6. Percent False } \\
\text { Starts Per Trial }\end{array}$ & & & & & & - \\
\hline
\end{tabular}

${ }^{*} p<.05$ (two-tailed), ${ }^{* *} p<.001$ (two-tailed) 
Table 13

Intercorrelations Between Sleep and Performance Variables: Week Eleven Postpartum

\begin{tabular}{|c|c|c|c|c|c|c|}
\hline & 1 & 2 & 3 & 4 & 5 & 6 \\
\hline $\begin{array}{l}\text { 1. Total } \\
\text { Sleep Time }\end{array}$ & - & -.19 & .13 & -.08 & -.12 & -.13 \\
\hline $\begin{array}{l}\text { 2. Sleep } \\
\text { Fragmentation }\end{array}$ & & - & $-.89 * *$ & -.06 & .01 & .06 \\
\hline $\begin{array}{l}\text { 3. Sleep } \\
\text { Efficiency }\end{array}$ & & & - & .22 & .16 & -.08 \\
\hline $\begin{array}{l}\text { 4. Mean Reaction } \\
\text { Time }\end{array}$ & & & & - & $.96 * *$ & -.29 \\
\hline $\begin{array}{l}\text { 5. Percent Lapses } \\
\text { Per Trial }\end{array}$ & & & & & - & -.20 \\
\hline $\begin{array}{l}\text { 6. Percent False } \\
\text { Starts Per Trial }\end{array}$ & & & & & & - \\
\hline
\end{tabular}

${ }^{* *} p<.001$ (two-tailed) 
Table 14

Intercorrelations Between Sleep and Performance Variables: Week Twelve Postpartum

\begin{tabular}{|c|c|c|c|c|c|c|}
\hline & 1 & 2 & 3 & 4 & 5 & 6 \\
\hline $\begin{array}{l}\text { 1. Total } \\
\text { Sleep Time }\end{array}$ & - & -.00 & .14 & -.18 & -.25 & -.03 \\
\hline $\begin{array}{l}\text { 2. Sleep } \\
\text { Fragmentation }\end{array}$ & & - & $-.90 * *$ & -.19 & -.10 & .06 \\
\hline $\begin{array}{l}\text { 3. Sleep } \\
\text { Efficiency }\end{array}$ & & & - & .11 & .04 & -.06 \\
\hline $\begin{array}{l}\text { 4. Mean Reaction } \\
\text { Time }\end{array}$ & & & & - & $.96 * *$ & -.20 \\
\hline $\begin{array}{l}\text { 5. Percent Lapses } \\
\text { Per Trial }\end{array}$ & & & & & - & -.10 \\
\hline $\begin{array}{l}\text { 6. Percent False } \\
\text { Starts Per Trial }\end{array}$ & & & & & & - \\
\hline
\end{tabular}

$* * p<.001$ (two-tailed) 
Table 15

Intercorrelations Between Sleep and Performance Variables: Week Thirteen Postpartum

\begin{tabular}{|c|c|c|c|c|c|c|}
\hline & 1 & 2 & 3 & 4 & 5 & 6 \\
\hline $\begin{array}{l}\text { 1. Total } \\
\text { Sleep Time }\end{array}$ & - & -.01 & .10 & -.05 & -.06 & -.26 \\
\hline $\begin{array}{l}\text { 2. Sleep } \\
\text { Fragmentation }\end{array}$ & & - & $-.85 * *$ & -.10 & -.07 & .15 \\
\hline $\begin{array}{l}\text { 3. Sleep } \\
\text { Efficiency }\end{array}$ & & & - & .10 & .08 & -.26 \\
\hline $\begin{array}{l}\text { 4. Mean Reaction } \\
\text { Time }\end{array}$ & & & & - & $.97 * *$ & -.13 \\
\hline $\begin{array}{l}\text { 5. Percent Lapses } \\
\text { Per Trial }\end{array}$ & & & & & - & -.07 \\
\hline $\begin{array}{l}\text { 6. Percent False } \\
\text { Starts Per Trial }\end{array}$ & & & & & & - \\
\hline
\end{tabular}

$* * p<.001$ (two-tailed) 
Table 16

Intercorrelations Between Sleep and Performance Variables: Week Fourteen Postpartum

\begin{tabular}{|c|c|c|c|c|c|c|}
\hline & 1 & 2 & 3 & 4 & 5 & 6 \\
\hline $\begin{array}{l}\text { 1. Total } \\
\text { Sleep Time }\end{array}$ & - & .17 & -.13 & -.09 & -.10 & -.24 \\
\hline $\begin{array}{l}\text { 2. Sleep } \\
\text { Fragmentation }\end{array}$ & & - & $-.91 * *$ & -.26 & -.16 & .16 \\
\hline $\begin{array}{l}\text { 3. Sleep } \\
\text { Efficiency }\end{array}$ & & & - & .25 & .19 & -.16 \\
\hline $\begin{array}{l}\text { 3. Mean Reaction } \\
\text { Time }\end{array}$ & & & & - & $.95 * *$ & -.25 \\
\hline $\begin{array}{l}\text { 4. Percent Lapses } \\
\text { Per Trial }\end{array}$ & & & & & - & -.15 \\
\hline $\begin{array}{l}\text { 5. Percent False } \\
\text { Starts Per Trial }\end{array}$ & & & & & & - \\
\hline
\end{tabular}

$* * p<.001$ (two-tailed) 
Table 17

Intercorrelations Between Sleep and Performance Variables: Week Fifteen Postpartum

\begin{tabular}{|c|c|c|c|c|c|c|}
\hline & 1 & 2 & 3 & 4 & 5 & 6 \\
\hline $\begin{array}{l}\text { 1. Total } \\
\text { Sleep Time }\end{array}$ & - & .23 & -.11 & -.02 & .03 & .04 \\
\hline $\begin{array}{l}\text { 2. Sleep } \\
\text { Fragmentation }\end{array}$ & & - & -.91 & -.33 & -.26 & .27 \\
\hline $\begin{array}{l}\text { 3. Sleep } \\
\text { Efficiency }\end{array}$ & & & - & .28 & .24 & -.13 \\
\hline $\begin{array}{l}\text { 4. Mean Reaction } \\
\text { Time }\end{array}$ & & & & - & $.96 * *$ & -.39 \\
\hline $\begin{array}{l}\text { 5. Percent Lapses } \\
\text { Per Trial }\end{array}$ & & & & & - & -.24 \\
\hline $\begin{array}{l}\text { 6. Percent False } \\
\text { Starts Per Trial }\end{array}$ & & & & & & - \\
\hline
\end{tabular}

$* * p<.001$ (two-tailed) 


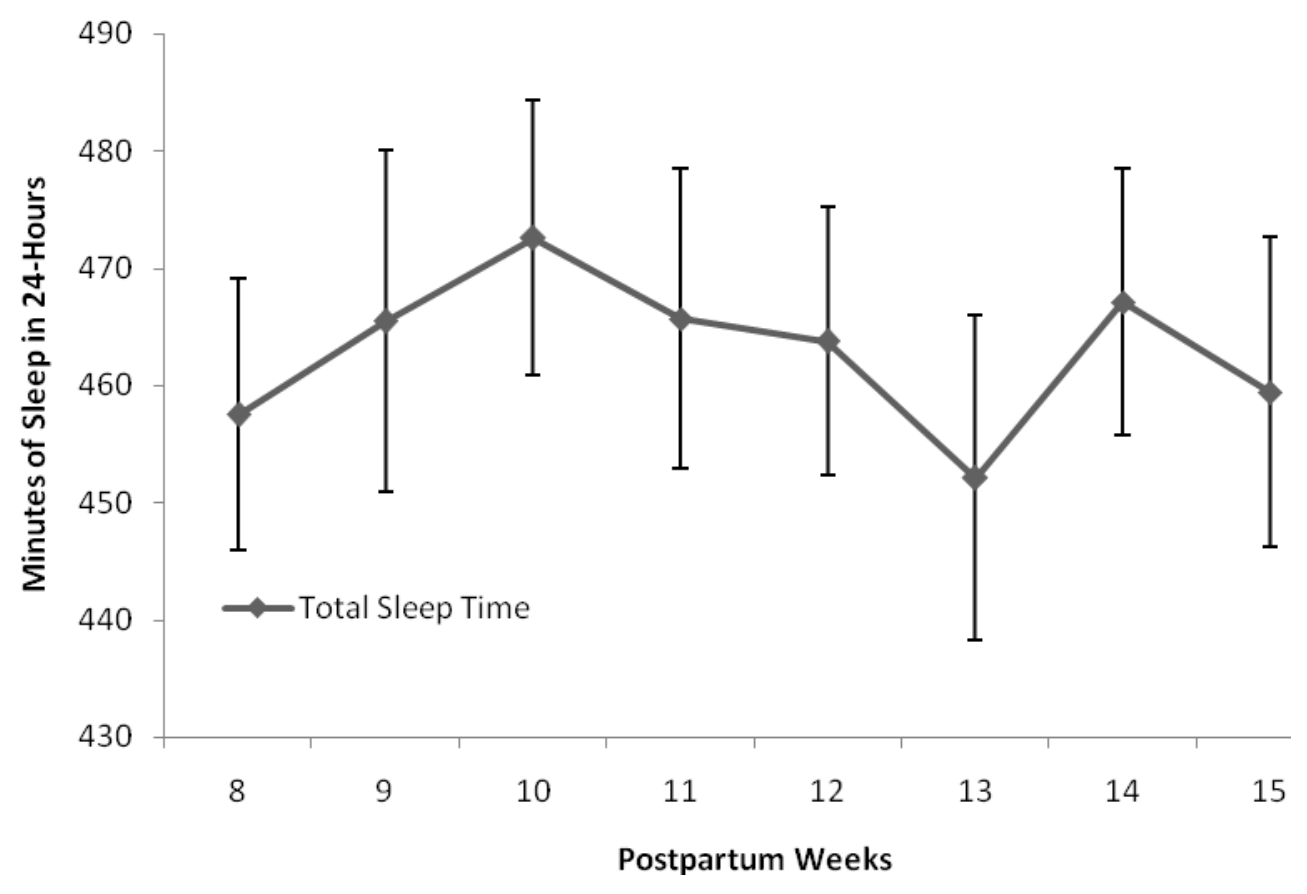

Figure 1. Average total sleep time with standard error bars across postpartum weeks eight through fifteen. 


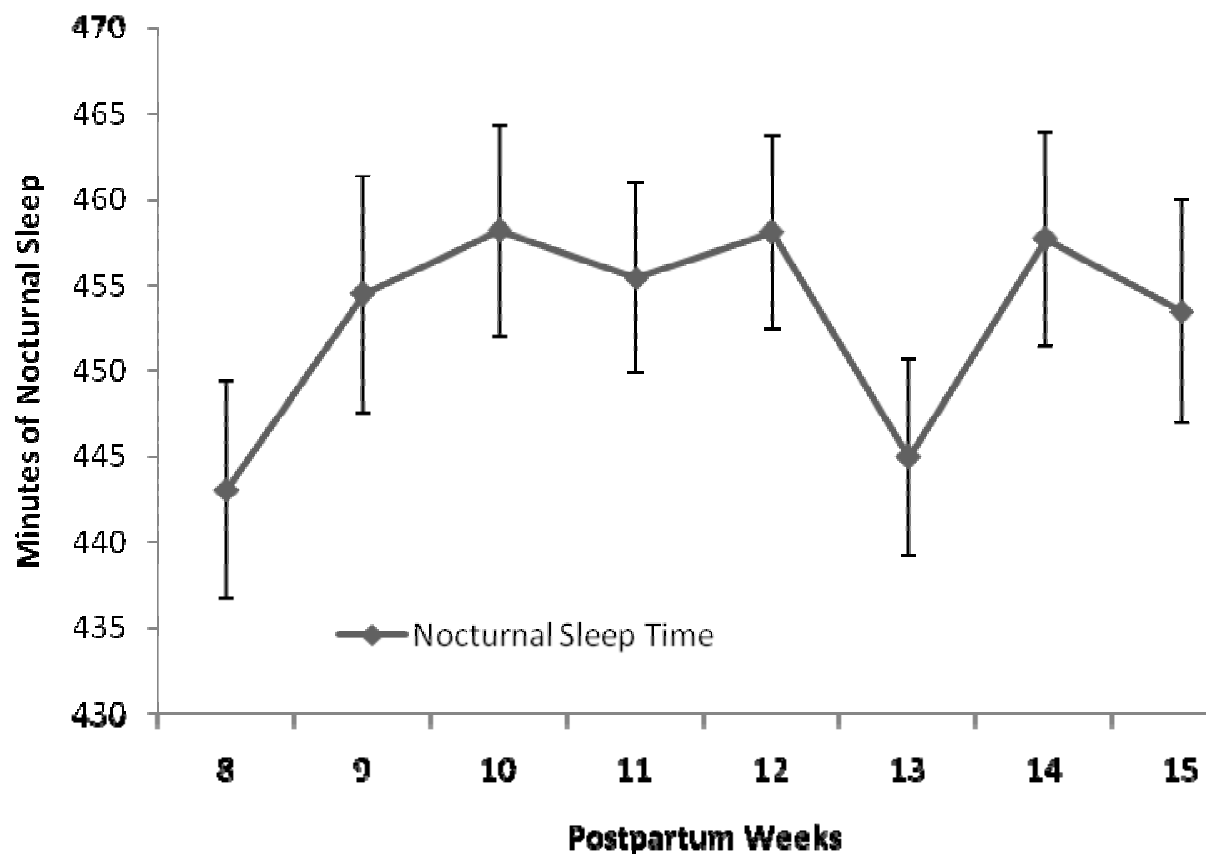

Figure 2. Average nocturnal sleep time with standard error bars across postpartum weeks eight through fifteen. 


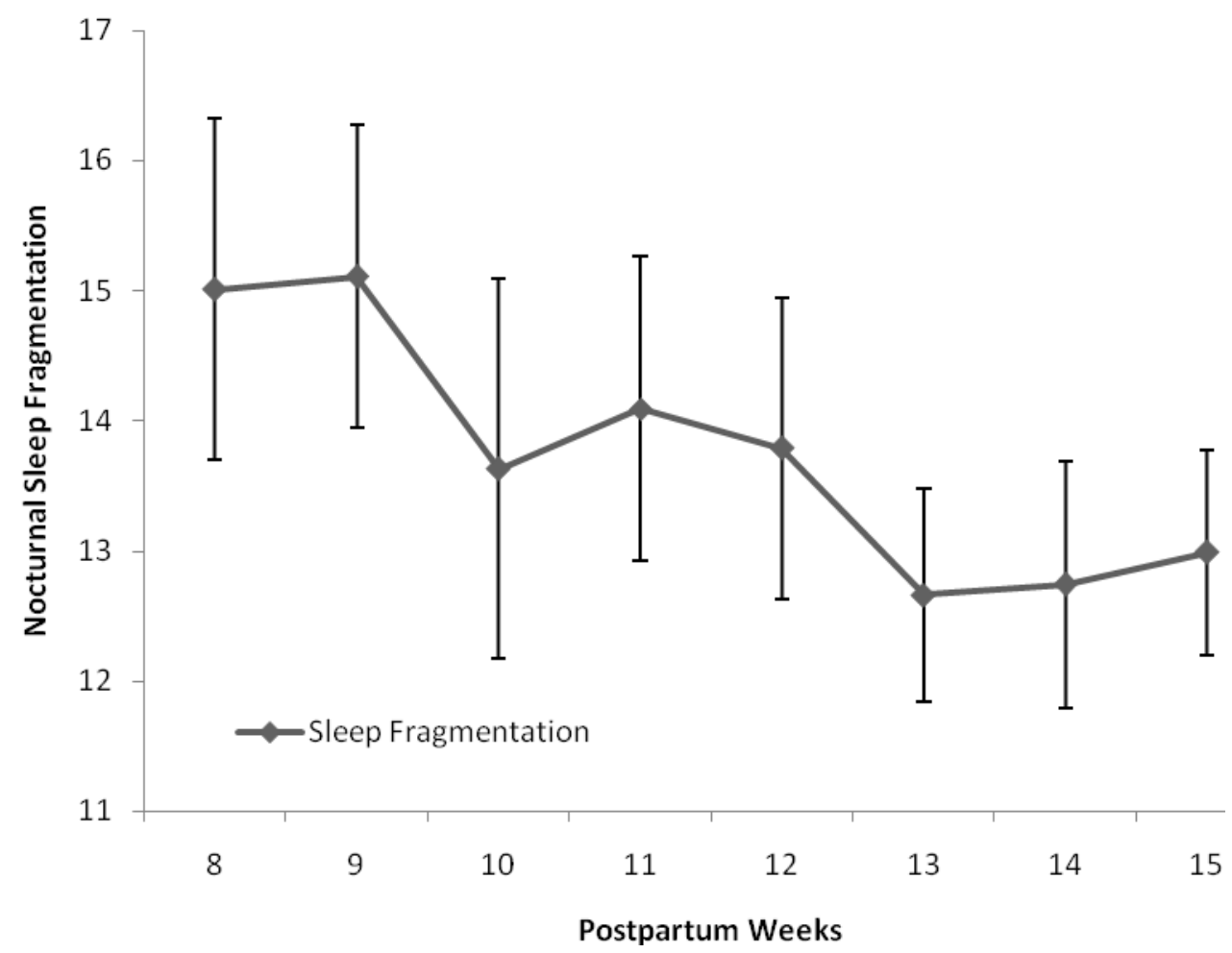

Figure 3. Average nocturnal sleep fragmentation with standard error bars across postpartum weeks eight through fifteen. 


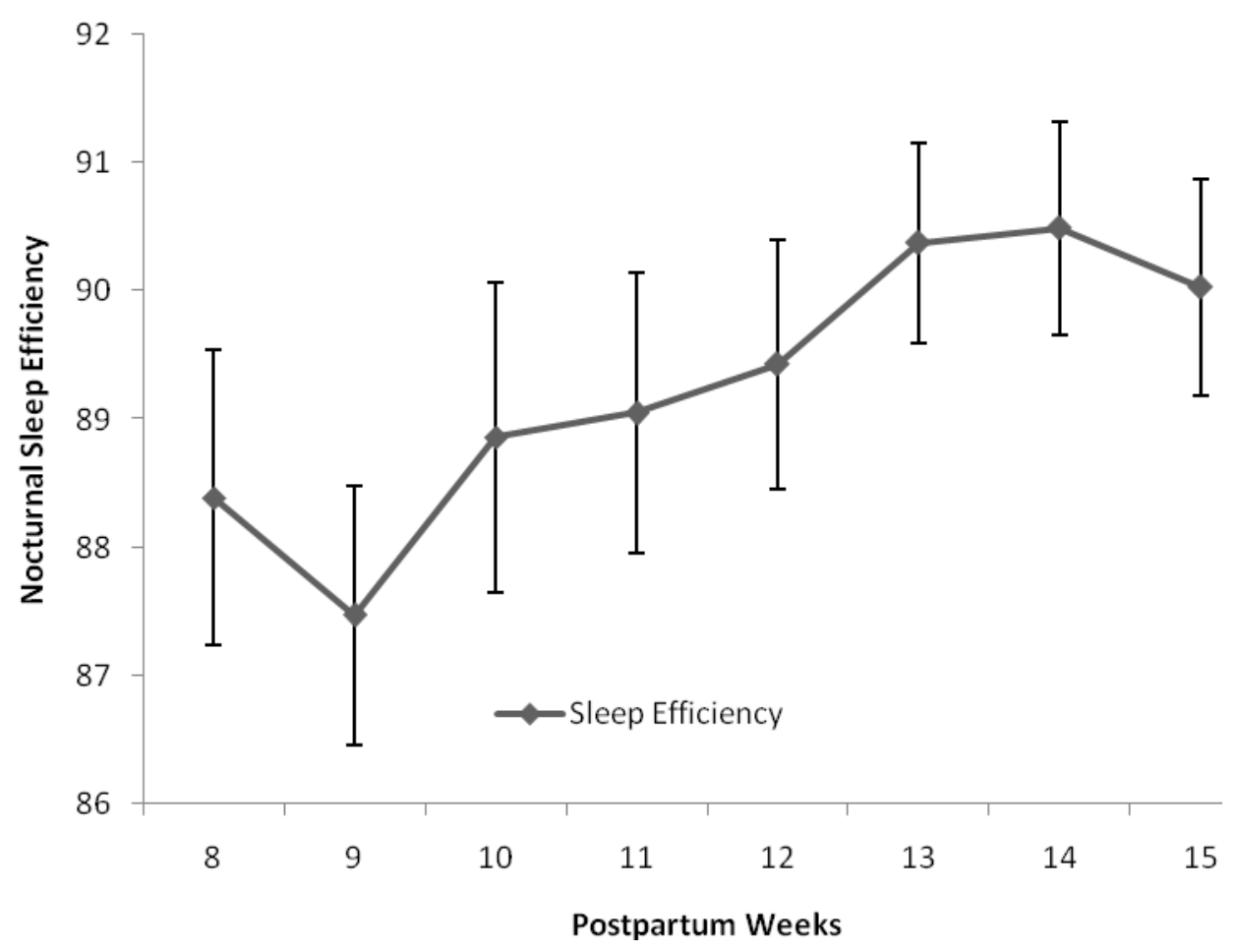

Figure 4. Average nocturnal sleep efficiency with standard error bars across postpartum weeks eight through fifteen. 


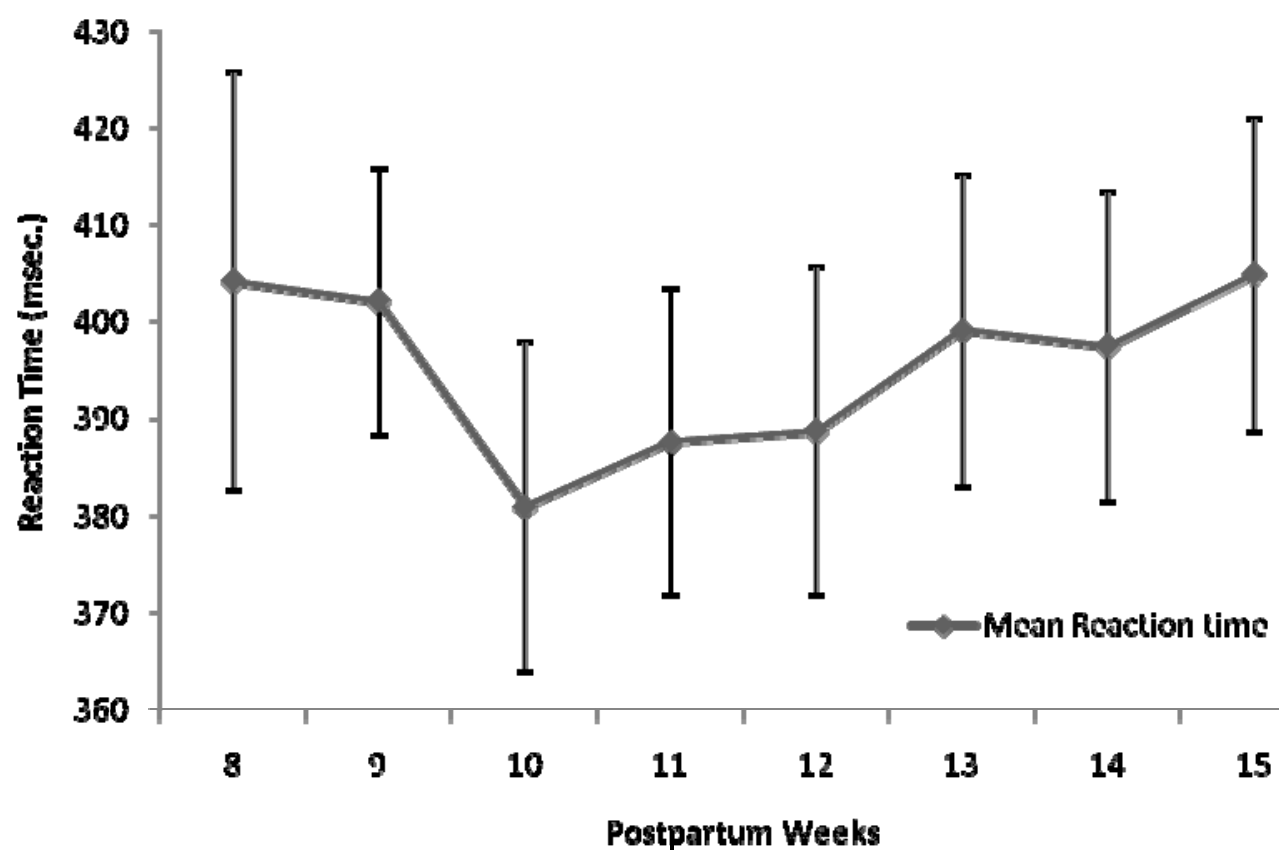

Figure 5. Average reaction time with standard error bars across postpartum weeks eight through fifteen. 


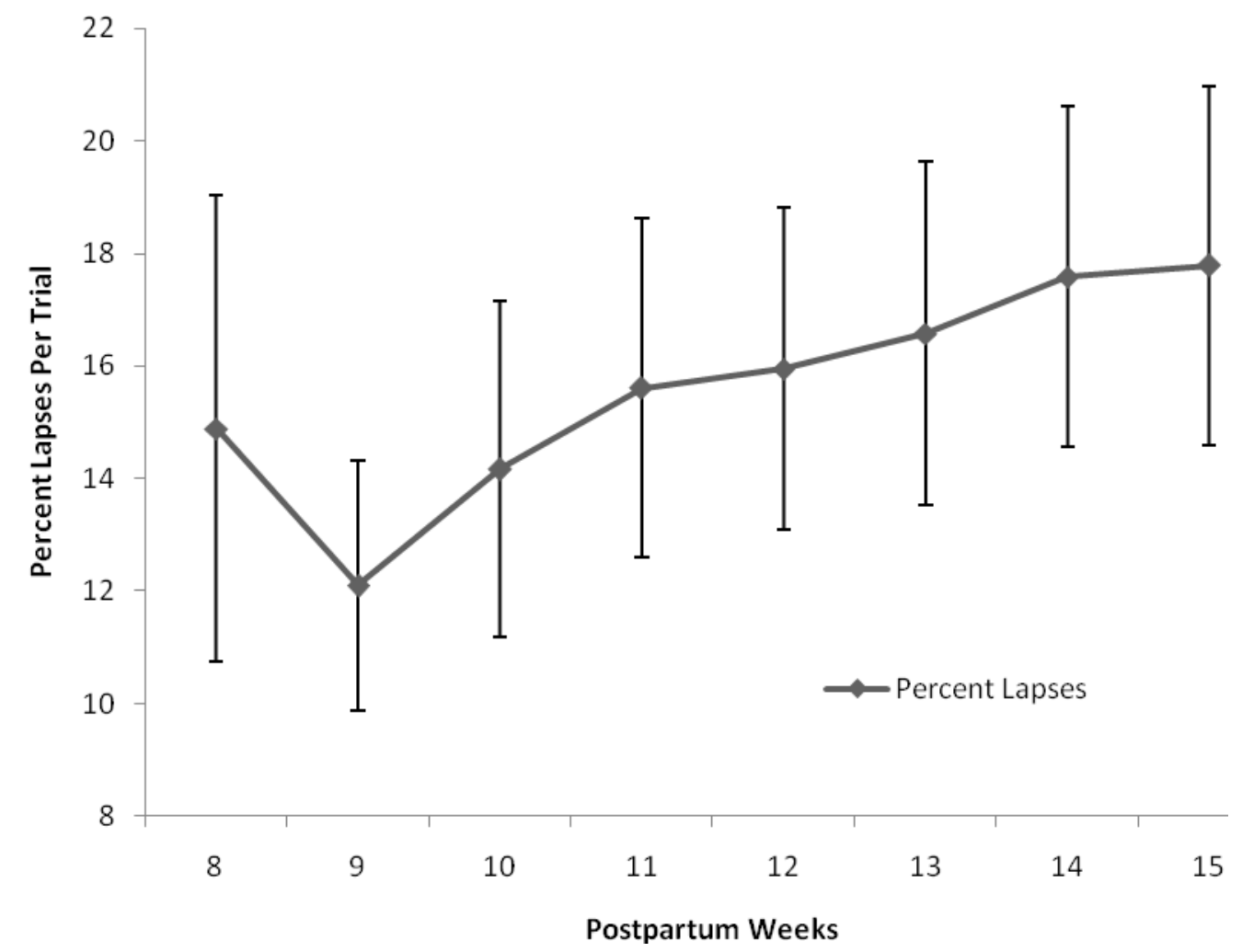

Figure 6. Percent lapses per trial with standard error bars across postpartum weeks eight through fifteen. 


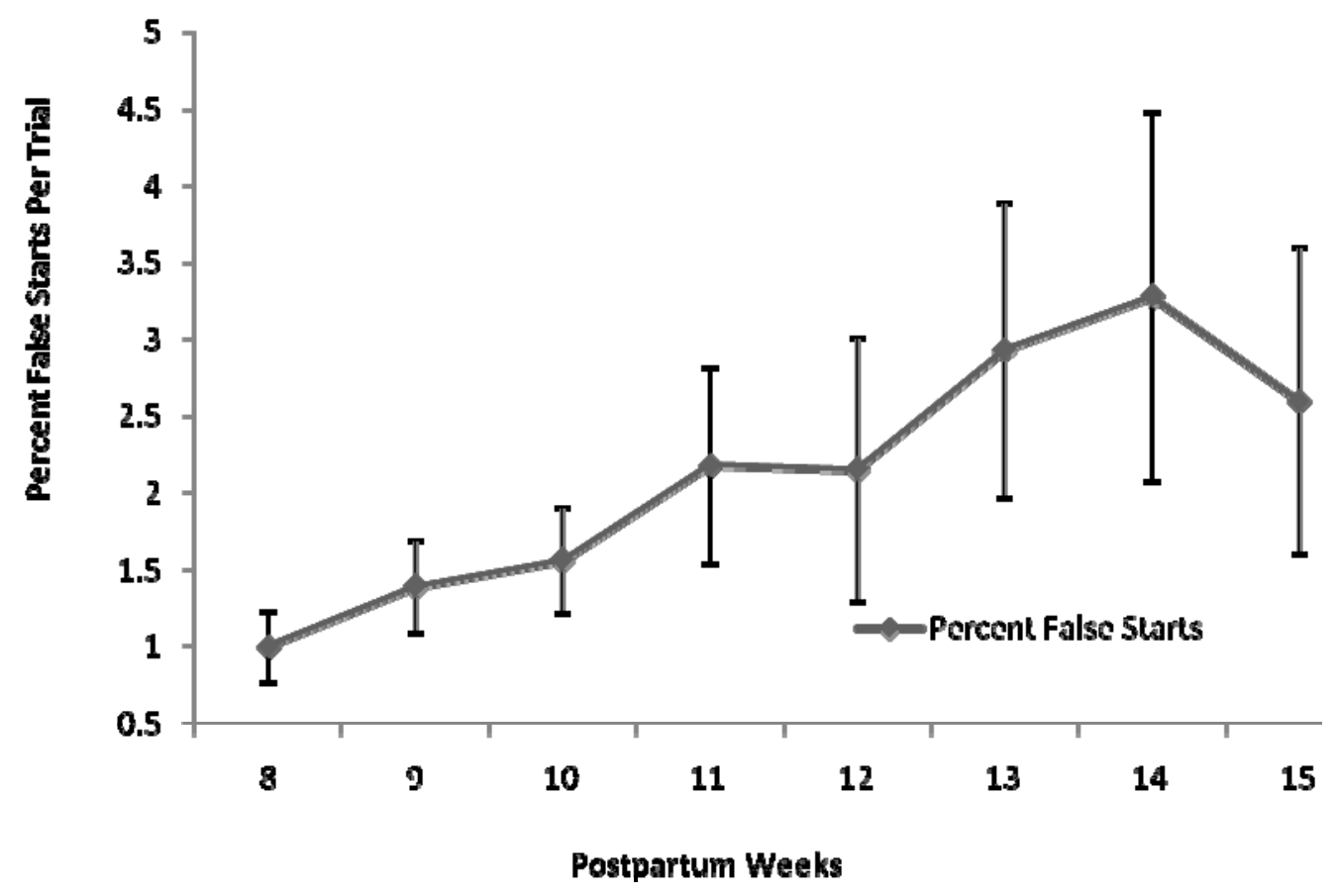

Figure 7. Percent false starts per trial with standard error bars across postpartum weeks eight through fifteen. 


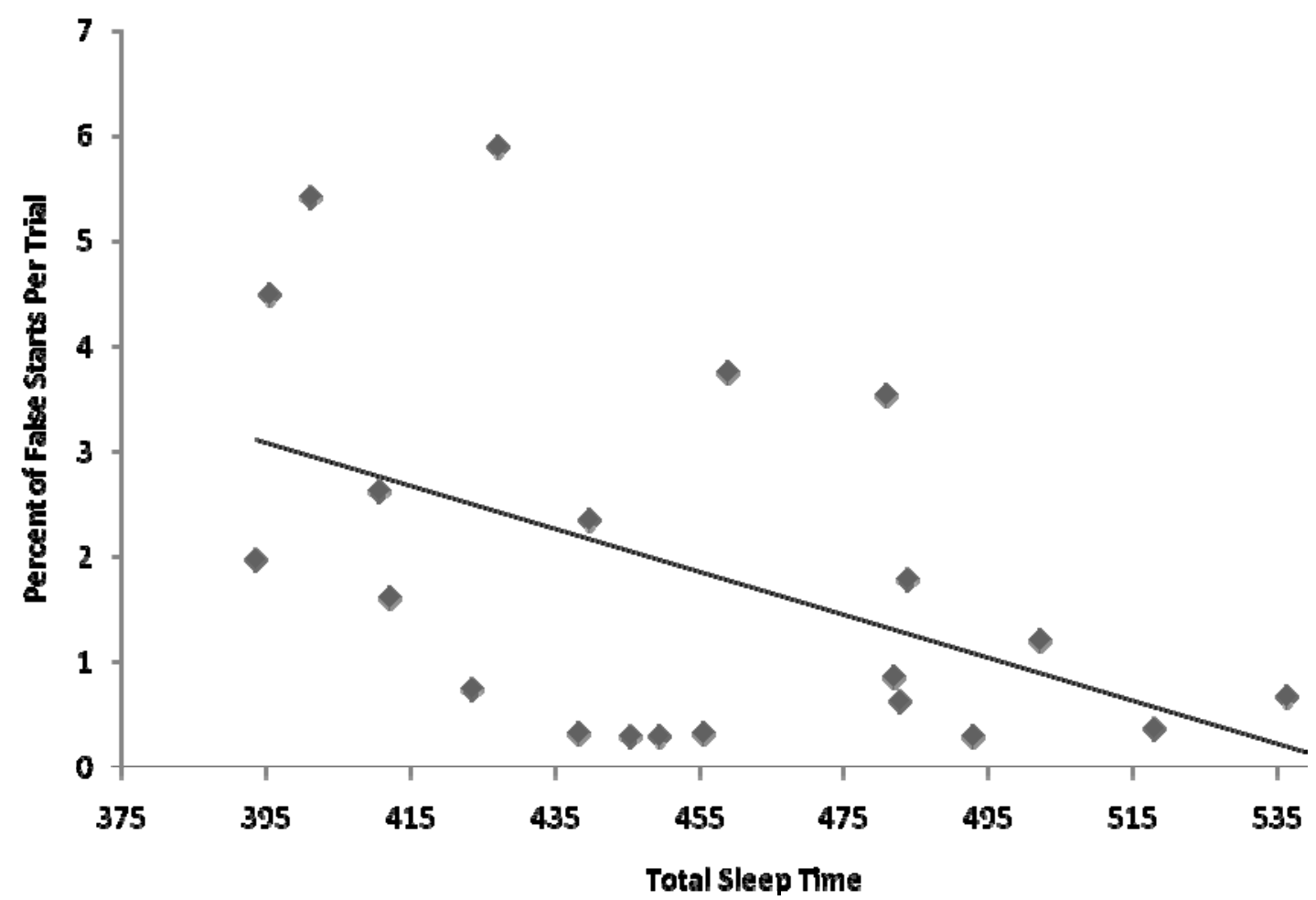

Figure 8. Scatter plot of total sleep time and percent false starts within postpartum week ten 